\title{
Kastamonu Yöresi Sarıçam Meşcereleri İçin Çap Dağılımlarının Modellenmesi ve Çeşitli Meşcere Özellikleri ile İlişkilerinin Belirlenmesi
}

\author{
Oytun Emre SAKICI ${ }^{1 *}$, Esra DAL ${ }^{2}$ \\ ${ }^{1 *}$ Kastamonu Üniversitesi, Orman Fakültesi, Orman Mühendisliği Bölümü, 37200, Kastamonu \\ ${ }^{2}$ Kastamonu Üniversitesi, Fen Bilimleri Enstitüsü, Orman Mühendisliği Anabilim Dalı, 37200, Kastamonu
}

\section{Öz}

Kastamonu yöresi sarıçam (Pinus sylvestris L.) meşcerelerinin çap dağılımlarının modellendiği bu çalışmada, bazı meşcere özelliklerinin (ağaç sayısı, orta çap, sıklık, bonitet sınıfı, kapalılık, gelişim çağı ve meşcere tipi) en uygun dağılım fonksiyonunun belirlenmesi üzerine olan etkileri de araştırılmıştır. Çalışmada Orman Genel Müdürlüğü arşivinden temin edilen 890 adet örnek alan verisinden yararlanılmış ve çap dağılımlarının modellenmesinde Beta, Gamma (2 ve 3 parametreli), Johnson SB, Log-normal (2 ve 3 parametreli), Normal ve Weibull (2 ve 3 parametreli) olasılık yoğunluk fonksiyonları kullanılmıştır. En başarılı dağılım fonksiyonunun belirlenmesinde KolmogorovSmirnov $(K S)$, Anderson-Darling $(A D)$, Ki-kare $\left(X^{2}\right)$ ve Hata İndeksi (e) ölçütleri kullanılmış ve fonksiyonlar bu ölçütlere göre her bir örnek alan için başarı sıralamasına tabi tutulmuştur. En uygun fonksiyonun seçimi üzerine meşcere özelliklerinin etkileri ise Kruskal-Wallis ve Ki-kare testleri yardımıyla değerlendirilmiştir. Sonuç olarak, Johnson SB fonksiyonunun en başarılı olasılık yoğunluk fonksiyonu olduğu belirlenmiştir. Olasılık yoğunluk fonksiyonlarının en başarılı bulunma durumları üzerinde ağaç sayısı, orta çap, kapalılık, gelişim çağı ve meşcere tipi etkili bulunurken, sıklık ve bonitet sınıfının herhangi bir etkisinin olmadığı belirlenmiştir.

Anahtar Kelimeler: Olasılık yoğunluk fonksiyonu, Johnson SB, maksimum olabilirlik yöntemi, rölatif sıralama, Pinus sylvestris.

\section{Modelling Diameter Distributions and Determination of Their Relationships with Some Stand Characteristics for Scots Pine Stands in Kastamonu Region}

\begin{abstract}
In this study, it was aimed to model the diameter distribution of Scots pine (Pinus sylvestris L.) stands in Kastamonu region. The effects of various stand characteristics (number of trees, mean diameter, stand density, site class, crown closure, developing stage and stand type) on the determination of the most appropriate distribution function were also investigated. 890 sample plots data obtained from the General Directorate of Forestry archive were utilized as study material, and Beta, Gamma (with 2 and 3 parameters), Johnson SB, Log-normal (with 2 and 3 parameters), Normal and Weibull (with 2 and 3 parameters) probability density functions were used to model the diameter distributions. Kolmogorov-Smirnov $(K S)$, Anderson-Darling $(A D)$, Chi-square $\left(X^{2}\right)$ and Error Index $(e)$ criteria were used to determine the success of probability density functions and to decide the most appropriate ones. The effects of stand characteristics on the decision of the most suitable function were also determined by Kruskal-Wallis and Chi-square tests. As a result of comparisons, Johnson SB was determined as the most successful probability density function. While the success of the probability density functions was affected by the number of trees, mean diameter, crown closure, developing stage and stand type, it was not affected by stand density and site class.
\end{abstract}

Keywords: Probability density function, Johnson SB, maximum likelihood method, relative ranking, Pinus sylvestris. 


\section{Giriş}

İnsanların ormanlardan talepleri ile ormanların bu talebi karşılama potansiyelleri arasındaki denge dikkate alındığında, ormanların sürdürülebilirlik ilkesi çerçevesinde ve optimal olarak işletilebilmesi için kullanılacak temel araç orman amenajman planlarıdır (Eraslan ve Şad, 1993; Eler, 2001; Kapucu, 2004; Asan, 2013). Orman amenajman planlarının düzenlenmesinde ihtiyaç duyulan en temel bilgiler ise büyüme ve artım verileri olup, bu veriler yardımıyla orman kaynaklarının büyüme ve artım potansiyelleri ile ormanların sunduğu ürün ve hizmetlerin geleceğe ilişkin projeksiyonları ortaya konulabilmektedir (Vanclay, 1994). Gerek ormanların planlanması ve gerekse planların uygulamaya aktarılması için ihtiyaç duyulan bu temel bilgiler büyüme ve artım modelleri yardımıyla elde edilebilirler (Gadow ve Hui, 1999). Bu modeller, modelleme ünitesinin büyüklüğüne bağlı olarak; (i) Meşcere Modelleri, (ii) Çap Sınıfı Modelleri ve (iii) Tek Ağaç Modelleri olmak üzere üç gruba ayrılmaktadır (Burkhart, 1979; Gadow ve Hui, 1999; Mısır, 2003). Meşcere modelleri modelleme ünitesi olarak meşcereleri temel alırken, tek ağaç modelleri meşcereleri oluşturan ağaçları münferit olarak ele almaktadır. Meşcere modelleri ile tek ağaç modellerinin arasında yer alan çap sınıfı modellerinde ise modelleme ünitesi olarak belirli çap aralıkları (1, 2 veya $4 \mathrm{~cm}$ gibi) ile oluşturulan çap basamakları temel alınmakta ve meşcereyi oluşturan ağaçların çap basamaklarına dağılımları modellenmektedir (Vanclay, 1994; Gadow ve Hui, 1999; Poudel ve Cao, 2013).

Tek ağaçlar veya meşcereler için geliştirilecek tüm modellerde kullanılabilecek değişkenler arasında en kolay ölçülebileni ağaçlara ilişkin çap değerleridir. Çap değişkeninin diğer hacim elemanları (boy, göğüs yüzeyi ve hacim gibi) ile yüksek korelasyon göstermesi söz konusu modelleme çalışmalarında öncelikle tercih edilen değişken olmasının bir diğer önemli nedenidir. Ayrıca, ormanlardan elde edilen odun kökenli ürün çeşitlerinin nicelik ve niteliklerinin belirlenebilmesinde de çap değerlerinden yararlanılmaktadır. Bu nedenlerle orman envanterinde ağaç çapları en önemli veri niteliğindedir (Nelson, 1964; Gadow ve Hui, 1999; Carus ve Çatal, 2008). Bunun yanında, ormancılığın gerek planlama ve gerekse işletmecilik aşamasındaki birçok uygulamasında ağaçların çap basamaklarına dağılımı ile ilgili bilgiler de büyük öneme sahiptir. Bu bilgiler, bir taraftan işletmeye konu ormanların çeşitli silvikültürel müdahaleler sonucunda ortaya çıkacak olası meşcere yapılarını ortaya koyarken, diğer taraftan işletme amaçlarına bağlı olarak odun üretimi fonksiyonunu üstlenen ormanlardan elde edilebilecek endüstriyel odunların nicelik, nitelik ve finansal getirileri ya da ekolojik fonksiyonla işletilen ormanların söz konusu ekolojik fonksiyonu karşılama potansiyeli hakkında öngörü sağlamaktadır (Hyink ve Moser, 1983; Rennols vd., 1985; Maltamo, 1997; Laar ve Akça, 2007; Gorgoso vd., 2012). Bunlara ilaveten, küresel iklim değişikliği ile mücadelenin temel araçlarından biri olan ormanlarda karbon depolama fonksiyonunu üstlenen orman biyokütlesinin miktarının ve depolanan karbon stoğunun ortaya konulmasında meşcerelerdeki çap dağılımı verilerinden yararlanılmaktadır (Chen, 2004; Özçelik vd., 2016).

Çap sınıfı modelleri, orman ekosistemlerinin temel unsuru olan ağaçları çap değerlerine göre gruplandırarak her bir gruba ilişkin ağaç sayılarının toplam ağaç sayısı içerisindeki dağılımının modellendiği büyüme modeli yapısıdır. Bu model yapısında ağaçlar çalışma amacına bağlı olarak 1,2 veya $4 \mathrm{~cm}$ gibi çap basamaklarına dağıtılarak her bir çap basamağındaki ağaç sayısı belirlenmekte ve elde edilen bu frekans dağılımı modellenmeye çalışılmaktadır (Vanclay, 1994; Gadow ve Hui, 1999). Bu modeller, meşcerelerdeki ağaçların çap basamaklarına dağılımını çeşitli dağılım fonksiyonları yardımıyla tahmin ederek meşcere yapısını belirlemek amacıyla kullanılırlar (Loetsch vd., 1973; Gorgoso vd., 2007).

Çap dağılımlarının modellenmesinde kullanılan yöntemler; (i) Parametrik Yöntemler ve (ii) Parametrik Olmayan Yöntemler olmak üzere iki gruba ayrılmaktadır. İlk grupta yer alan modeller çap dağılımını önceden tanımlanmış olasılık yoğunluk fonksiyonları ile modellerken, ikinci gruptaki modellerde ise çap dağılımları çap basamaklarındaki ağaç yüzdelerinin tahmin edilmesi yöntemi veya en yakın $k$ adet komşu ağaç sayısına dayanan yöntem gibi yaklaşımlarla önceden belirlenmiş herhangi bir matematiksel fonksiyondan yararlanmadan modellenmektedir (Duan vd., 2013). Çap dağılımlarının modellenmesi ile ilgili çalışmaların tarihsel gelişim sürecine bakıldığında; Loetsch vd. (1973) ve Packard (2000) bu konudaki çalışmaların 1900’lü yıllardan daha önce başladığını, 1930’lu yıllarda matematiksel serilerden yararlanıldığını ve 1960'lı yıllardan itibaren de olasılık yoğunluk fonksiyonlarının kullanımının öne çıktığını ifade etmişlerdir.

Çap sınıfı modelleri için en çok tercih edilen olasılık yoğunluk fonksiyonları; Beta, Gamma, Johnson SB, Normal, Log-normal ve Weibull fonksiyonlarıdır (Bailey ve Dell, 1973; Rennols vd., 1985; Maltamo, 1997; Liu vd., 2002). Uluslararası literatürde bunlara örnek olarak; Beta dağılımı için Clutter ve Bennet (1965), Maltamo vd. (1995), Cao (1997) ve Gorgoso-Varela vd. (2008), Gamma dağılımı için Nelson (1964) ve Bailey (1980), Johnson SB dağılımı için Hafley ve Schreuder (1977), Scolforo vd. (2003), Siipilehto vd. (2007), Fonseca vd. (2009) ve Mayrinck vd. (2018), Normal dağılım için Clutter ve Bennet (1965) ve Bailey (1980), Log-normal dağılım için Bliss ve Reinker (1964) ve Lima vd. (2017) ve Weibull dağılımı için Bailey ve Dell (1973), Magnussen (1986), 
Maltamo vd. (1995), Gorgoso vd. (2012), Diamantopoulou vd. (2015) ve Pogoda vd. (2019) verilebilir. Ulusal literatürde ise; Carus (1996) ve Güneş (2015) Gamma dağılımını, Ercanlı ve Yavuz (2010), Sönmez vd. (2010), Kahriman ve Yavuz (2011), Doğdaş (2014), Özçelik vd. (2016), Alkan (2019), Bolat (2021), Sakıc1 (2021) ve Seki (2021) Johnson SB dağılımını, Carus ve Çatal (2008) ve Carus ve Çatal (2011) Log-normal dağılımı ve Ercanlı ve Yavuz (2010), Sakıcı ve Gülsunar (2012), Ercanlı vd. (2013), Bolat (2014), Özdemir (2016), Sakıcı vd. (2016) ve Sivrikaya ve Karakaş (2020) Weibull dağılımını başarılı bulmuşlardır.

Çap dağılımlarının modellenmesinde hangi dağılım fonksiyonunun kullanılacağına karar verilmesi oldukça önemlidir. Liu vd. (2014), tüm dağılım fonksiyonlarının güçlü ve zayıf yönlerinin bulunduğunu ve herhangi bir dağılım fonksiyonunun kullanılabilirliğinin meşcere yapısını tanımlayan çeşitli meşcere özelliklerine bağlı olduğunu, Wang ve Rennolls (2005) ise bu fonksiyonların meşcere özelliklerine bağlı olarak kimi durumlarda oldukça başarılı sonuçlar verirken kimi durumlarda ise başarısız olabileceğini ifade etmişlerdir. Çap dağılımlarının başarılı bir şekilde modellenmesi, en uygun dağılım fonksiyonunun seçilmesinin yanında, seçilen dağılım fonksiyonunun parametrelerinin başarılı şekilde tahmin edilmesine de bağlıdır (Poudel ve Cao, 2013). Fonksiyonların parametrelerinin belirlenmesinde kullanılan yöntemler; (i) Parametre Tahmin Yöntemi ve (ii) Parametre Çözümleme Yöntemi olmak üzere iki gruba ayrılmaktadır (Hyink ve Moser, 1983; Gadow ve Hui, 1999; Siipilehto vd., 2007). İlk yöntemde, çeşitli meşcere özellikleri ile fonksiyon parametreleri arasındaki ilişkiler ampirik olarak ortaya konulmakta iken, ikinci yöntemde öncelikle meşcere özellikleri ile çap dağılımlarına ilişkin yüzdeler ya da momentler arasındaki ilişkiler belirlenmekte ve fonksiyon parametreleri de bu ilişkilere bağlı olarak çözümlenmektedir (Bailey vd., 1981; Burk ve Newberry, 1984; Brooks vd., 1992; Kangas ve Maltamo, 2000; Gorgoso vd., 2007; Burkhart ve Tomé, 2012). Sonuç olarak; çap dağılımlarının modellenmesinde kullanılacak dağılım fonksiyonlarının seçiminde dağılım şeklinin başarılı bir şekilde ortaya konulabilmesi, dağılım fonksiyonunun parametre tahmininin kolay yapılabilmesi, farklı çap basamaklarındaki oranların tahmininde kullanılan çözümleme yönteminin basit olması ve dağılımlara ilişkin tahmin başarılarının yüksek olması gibi kriterlerin dikkate alınması gerekmektedir (Hafley ve Schreuder, 1977).

Çap dağılımlarının modellenmesi ile ilgili araştırmalarda genellikle iki temel konu üzerinde durulduğu görülmektedir. Bunlardan ilki en uygun dağılım fonksiyonuna karar verilmesi, diğeri ise kararlaştırılan dağılım fonksiyonunun parametrelerinin belirlenmesinde en uygun yöntemin seçilmesidir. Bu çalışmada, Kastamonu yöresi sarıçam (Pinus sylvestris L.) meşcereleri için çeşitli meşcere özelliklerine (ağaç sayısı, orta çap, sıklık, bonitet sınıfı, gelişim çağı, kapalılık ve meşcere tipi) bağlı olarak çap dağılımlarının modellenmesinde en uygun dağılım fonksiyonunun istatistiksel karşılaştırma ölçütleri yardımıyla belirlenmesi amaçlanmıştır. Bu amaçla, ormancılık literatüründe sıklıkla tercih edilen Beta, Gamma, Johnson SB, Normal, Log-normal ve Weibull dağılımları karşılaştırılmıştır.

\section{Materyal ve Metot}

\subsection{Materyal}

Ülkemizde yaklaşık 0,9 milyon ha normal kapalı ve yaklaşık 0,5 milyon ha boşluklu kapalı olmak üzere toplam 1,4 milyon ha'ın üzerinde bir yayılış alanına sahip olan sarıçam (Pinus sylvestris L.), iğne yapraklı ağaçlar arasında kızılçam ve karaçamdan sonra en geniş yayılış alanına sahip ağaç türüdür ve 22,9 milyon ha olan ülkemiz toplam orman varlığının \%6,15'lik kısmını oluşturmaktadır (OGM, 2021). Toplam yüzölçümü 1,3 milyon ha'ın üzerinde olan Kastamonu, ülkemizin orman varlığ bakımından en zengin illerinden biri olup, ilin toplam orman varlığı OGM (2021) verilerine göre 873.651 ha'dır. Çalışmaya konu edilen Kastamonu ili saf sarıçam meşcerelerinin alansal büyüklüğü ise 61.510 ha (45.897 ha normal kapalı ve 15.613 ha boşluklu kapalı) olup Kastamonu ormanlarının yaklaşık \% 7'sini oluşturmaktadır.

Kastamonu ili saf sarıçam meşcerelerinin çeşitli meşcere özelliklerine (ağaç sayısı, orta çap, sıklık, bonitet sınıfı, gelişim çağı, kapalılık ve meşcere tipi) bağlı olarak çap dağılımlarının modellenmesinin amaçlandığı bu çalışmada, çalışma materyali olarak söz konusu meşcere özellikleri bakımından farklılık gösteren meşcerelere ilişkin örnek alan verilerine ihtiyaç duyulmuştur. Bu veriler, çalışma alanındaki Orman İşletme Şefliklerinde halihazırda kullanılan orman amenajman planlarının hazırlanması için 2008-2013 yılları arasında gerçekleştirilen arazi çalışmaları ile alınan ve Orman Genel Müdürlüğü’ne bağlı Orman İdaresi ve Planlama Dairesi Başkanlığı arşivinde bulunan örnek alan karnelerinden temin edilmiştir. Bu amaçla, öncelikle saf sarıçam meşcerelerinden alınmış 2.346 adet örnek alan karnesi seçilmiştir. Çalışma, farklı meşcere özelliklerine göre çap dağılımlarının incelenmesi amacıyla yürütüldüğünden örnek alanlara ait bonitet sınıfları ve meşcere tipleri, meşcere özellikleri farklılıklarının tanımlanmasında kullanılmıştır. Sözü edilen farklılıkların çap dağılımları üzerindeki etkisinin başarılı şekilde ortaya konulabilmesi için her meşcere tipinin farklı bonitet sınıflarından 30'ar adet örnek alan 
seçilmesi kararlaştırılmıştır. Arşivden temin edilen örnek alan karnelerinin meşcere özelliklerine dağılımlarının elverdiği ölçüde bu karara uyulmuş, diğer durumlarda ise maksimum sayıda örnek alan alınması yoluna gidilmiş ve sonuç olarak 890 adet örnek alan karnesinin çalışmada kullanılabileceğine karar verilmiştir.

Çalışmada kullanılmak üzere seçilen örnek alanların büyüklükleri meşcere kapalılığına bağlı olarak genellikle 1 kapalı meşcerelerde $800 \mathrm{~m}^{2}, 2$ kapalı meşcerelerde $600 \mathrm{~m}^{2}$ ve 3 kapalı meşcerelerde $400 \mathrm{~m}^{2}$ olmakla birlikte bazı örnek alanların büyüklükleri örnek alana meşcereyi temsil edecek sayıda örnek ağaç düşmemesinden dolayı örnek alanın büyütülmesi veya örnek alana oldukça fazla sayıda örnek ağaç düşmesinden dolayı örnek alanın küçültülmesi nedenleriyle bu kuralın dışında kalmıştır.

Örnek alan karnelerinde;

- Çapları $8 \mathrm{~cm}$ ve daha kalın olan ağaçların çap değerleri,

- Çapları ölçülen ağaç sayıları,

- Gelişim çağları (b, bc, c, cd ve d),

- Alemdağ (1967) tarafindan düzenlenen bonitet endeks tablosuna göre belirlenen bonitet sınıfları (I. bonitet: 14,5-20,5 m, II. bonitet: 20,5-26,5 m ve III. bonitet: 26,5-32,5 m),

- Örnek alandaki ağaçların toprağı örtme dereceleri yardımıyla belirlenen kapalılık sınıfları (1 kapalı: \%11-40, 2 kapalı: \%41-70 ve 3 kapalı: >\%70),

- Gelişim çağı ile kapalılık sınıfı özelliklerinin birlikte kullanılmasıyla belirlenen meşcere tipleri bilgileri yer almaktadır.

Çalışmada değerlendirilen meşcere özelliklerinden bonitet sınıfı, gelişim çağı, kapalılık ve meşcere tipi doğrudan örnek alan karnelerinden alınırken, ağaç sayısı, orta çap ve sıklık ise karnelerden elde edilen bilgilerden yararlanılarak her bir örnek alan için aşağıdaki eşitlikler yardımıyla hesaplanmıştır. Sıklık değerinin belirlenmesi için kullanılan eşitlik Curtis vd. (1981) tarafindan geliştirilmiş olan sıklık derecesi eşitliğidir.

$$
\begin{aligned}
& N=\frac{10000}{\ddot{O} A B} n \\
& d_{q}=\sqrt{\frac{\sum d_{i}^{2}}{n}} \\
& S D=\frac{\frac{\pi}{4} \sum d_{i}^{2}}{\sqrt{d_{q}}}
\end{aligned}
$$

$\mathrm{Bu}$ eşitliklerde; $N$ ağaç sayısını (adet/ha), $n$ örnek alandaki ağaç sayısını (adet), ÖAB örnek alan büyüklüğünü $\left(\mathrm{m}^{2}\right), d_{q}$ meşcere orta çapını $(\mathrm{cm}), d_{i}$ örnek alanlardaki ağaçların göğüs yüksekliği çaplarını $(\mathrm{cm})$ ve $S D$ sıklık derecesini ifade etmektedir.

Çalışmada kullanılan örnek alanların meşcere özelliklerine ilişkin istatistiksel değerler Tablo 1'de verilmiştir. Tabloda da görüleceği üzere, I. bonitet sınıfında Çsbc1 ve III. bonitet sınıfında Çsb1 meşcereleri için örnek alan karnesi temin edilemediğinden bu özelliklerdeki meşcereler çalışmaya dahil edilememiştir.

\subsection{Metot}

Ormancılık alanında yapılan çeşitli uygulama ve araştırmaların temel verilerinden birisi olan çap değerleri ölçüm yoluyla elde edilen ve belirli bir tanım aralığı için tüm değerleri alabilen bir değişken olduğundan sürekli rastgele değişken özelliği taşımaktadır. Herhangi bir çap değerinin ilgilenilen meşcerede bulunma olasılığının ve çap değerlerinin frekans dağılımlarının ortaya konulmasında sürekli değişkenler için geliştirilen olasılık yoğunluk fonksiyonlarından yararlanılmaktadır. Bu fonksiyonlar, herhangi bir çap değerini (30 $\mathrm{cm}$ gibi) veya belirli aralıklarla oluşturulmuş çap sınıflarına ilişkin değerleri $(28-32 \mathrm{~cm}$ aralı̆̆ kullanarak ilgili çap değerine sahip ağaçların sayısının meşceredeki toplam ağaç sayısına oranını tahmin etmek üzere kullanılırlar. Söz konusu oranın meşceredeki toplam ağaç sayısı ile çarpılmasıyla da ilgili çap veya çap sınıfı değerine sahip ağaç sayısı belirlenmektedir. 
Tablo 1. Örnek alanlara ilişkin çeşitli istatistiksel bilgiler.

\begin{tabular}{|c|c|c|c|c|c|c|c|c|c|c|c|}
\hline \multirow{2}{*}{$\begin{array}{l}\text { Bonitet } \\
\text { Sinıfi }\end{array}$} & \multirow{2}{*}{$\begin{array}{c}\text { Meşcere } \\
\text { Tipi }\end{array}$} & \multirow{2}{*}{$\begin{array}{c}\text { Örnek Alan } \\
\text { Sayısı }\end{array}$} & \multicolumn{3}{|c|}{ Orta Çap (cm) } & \multicolumn{3}{|c|}{ Ağaç Sayısı (adet/ha) } & \multicolumn{3}{|c|}{ Sıklık Derecesi } \\
\hline & & & $\overline{\text { Ort. (Std. S.) }}$ & Min. & Mak. & Ort. (Std. S.) & Min. & Mak. & Ort. (Std. S.) & Min. & Mak. \\
\hline \multirow[t]{15}{*}{$\mathbf{I}$} & Çsb1 & 3 & $15,2(3,5)$ & 11,8 & 18,7 & $271,0(111,9)$ & 200 & 400 & $1,18(0,24)$ & 0,91 & 1,35 \\
\hline & Çsb2 & 2 & $12,5(1,6)$ & 11,3 & 13,6 & $1025,0(176,8)$ & 900 & 1150 & $3,61(1,29)$ & 2,69 & 4,52 \\
\hline & Çsb3 & 30 & $13,6(1,9)$ & 9,7 & 18,3 & $1130,3(594,1)$ & 333 & 3450 & $4,33(1,80)$ & 0,79 & 9,95 \\
\hline & Çsbc1 & - & - & - & - & - & - & - & - & - & - \\
\hline & Çsbc2 & 5 & $18,9(4,9)$ & 12,7 & 25,7 & $490,0(128,5)$ & 350 & 667 & $3,40(2,05)$ & 1,24 & 6,80 \\
\hline & Çsbc3 & 30 & $18,1(2,5)$ & 13,4 & 24,2 & $1082,8(443,5)$ & 400 & 2450 & $6,34(2,35)$ & 2,71 & 11,88 \\
\hline & Çsc1 & 3 & $20,1(2,5)$ & 17,2 & 21,7 & $258,7(75,4)$ & 188 & 338 & $1,77(0,28)$ & 1,45 & 1,98 \\
\hline & Çsc2 & 17 & $24,9(2,4)$ & 19,7 & 29,5 & $481,4(147,6)$ & 263 & 800 & $4,65(1,45)$ & 2,25 & 7,43 \\
\hline & Çsc3 & 30 & $24,5(3,6)$ & 16,5 & 34,4 & $720,8(233,9)$ & 400 & 1225 & $6,67(1,79)$ & 3,16 & 10,50 \\
\hline & Çscd1 & 11 & $29,5(3,8)$ & 24,1 & 36,6 & $208,6(78,0)$ & 75 & 325 & $2,65(1,08)$ & 0,84 & 3,98 \\
\hline & Çscd2 & 30 & $29,0(4,3)$ & 21,3 & 37,5 & $437,9(156,7)$ & 183 & 850 & $5,18(1,51)$ & 2,51 & 10,22 \\
\hline & Çscd3 & 30 & $29,8(3,6)$ & 21,2 & 35,1 & $618,3(157,6)$ & 300 & 925 & $7,66(1,26)$ & 4,18 & 10,40 \\
\hline & Çsd1 & 9 & $40,6(5,6)$ & 30,6 & 49,2 & $141,4(86,8)$ & 50 & 288 & $2,68(1,28)$ & 1,00 & 4,14 \\
\hline & Çsd2 & 25 & $39,5(3,8)$ & 32,5 & 48,1 & $295,8(91,6)$ & 150 & 533 & $5,68(1,61)$ & 2,77 & 9,98 \\
\hline & Çsd3 & 18 & $35,7(4,9)$ & 27,5 & 45,5 & $398,6(134,0)$ & 200 & 775 & $6,46(1,61)$ & 3,93 & 10,54 \\
\hline \multirow[t]{15}{*}{ II } & Çsb1 & 2 & $12,0(0,6)$ & 11,6 & 12,4 & $350,5(17,7)$ & 338 & 363 & $1,15(0,13)$ & 1,05 & 1,24 \\
\hline & Çsb2 & 3 & $15,8(2,7)$ & 14,2 & 18,9 & $477,7(203,7)$ & 300 & 700 & $2,24(0,64)$ & 1,81 & 2,98 \\
\hline & Çsb3 & 30 & $13,3(2,0)$ & 9,8 & 16,8 & $1435,0(411,0)$ & 525 & 2250 & $5,34(1,50)$ & 2,68 & 9,59 \\
\hline & Çsbc1 & 7 & $18,8(4,1)$ & 12,1 & 24,0 & $347,6(168,4)$ & 150 & 700 & $2,05(0,57)$ & 1,22 & 2,77 \\
\hline & Çsbc2 & 23 & $18,3(2,9)$ & 10,9 & 24,0 & $619,8(46$ & 113 & 2600 & $3,43(1,29)$ & 1,00 & 7,37 \\
\hline & Çsbc3 & 30 & $17,6(3,0)$ & 11,4 & 23,7 & $1135,0(295,3)$ & 625 & 1750 & $6,57(2,19)$ & 2,31 & 11,75 \\
\hline & Çsc1 & 5 & $20,9(3,9)$ & 16,7 & 27,2 & $351,6(81,9)$ & 233 & 450 & $2,70(1,12)$ & 1,75 & 4,46 \\
\hline & Çsc2 & 30 & $24,1(3,2)$ & 19,2 & 29,9 & 426,3 (1 & 200 & 833 & $3,88(1,27)$ & 1,37 & 6,20 \\
\hline & Çsc3 & 30 & $23,1(3,2)$ & 16,4 & 30,2 & $788,3(177,1)$ & 450 & 1150 & $6,81(1,61)$ & 3,12 & 10,99 \\
\hline & Çscd1 & 29 & $31,1(5,8)$ & 20,0 & 40,6 & $241,6(80,4)$ & 113 & 438 & $3,23(1,03)$ & 1,24 & 4,95 \\
\hline & Çscd2 & 30 & $29,9(4,4)$ & 21,8 & 39,0 & 408,3 (121,8) & 167 & 667 & $5,09(1,21)$ & 2,10 & 7,13 \\
\hline & Çscd3 & 30 & $28,9(5,2)$ & 20,9 & 41,6 & $687,2(197,1)$ & 400 & 1325 & $8,05(1,67)$ & 5,65 & 14,38 \\
\hline & Çsd1 & 24 & $43,4(8,1)$ & 30,9 & 62,6 & $153,5(79,0)$ & 63 & 400 & $3,17(0,97)$ & 1,82 & 5,40 \\
\hline & Çsd2 & 30 & $37,8(6,0)$ & 24,5 & 49,9 & $294,1(125,1)$ & 138 & 617 & $5,04(1,41)$ & 2,32 & 7,88 \\
\hline & Çsd3 & 21 & $37,8(4,7)$ & 27,8 & 47,5 & $474,5(215,1)$ & 150 & 1033 & $8,19(2,82)$ & 3,49 & 14,67 \\
\hline \multirow[t]{15}{*}{ III } & Çsb1 & 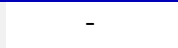 & - & - & - & - & - & - & 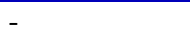 & - & - \\
\hline & Çsb2 & 9 & $12,7(2,5)$ & 9,7 & 16,7 & $542,7(130,9)$ & 400 & 750 & $1,89(0,45)$ & 1,07 & 2,44 \\
\hline & Çsb3 & 30 & $13,2(1,9)$ & 10,7 & 19,1 & $1080,3(452,1)$ & 483 & 2450 & $3,89(1,18)$ & 2,08 & 6,77 \\
\hline & Çsbc1 & 27 & $17,7(3,1)$ & 12,2 & 23,4 & $343,0(204,1)$ & 113 & 925 & $1,81(0,61)$ & 1,00 & 3,11 \\
\hline & Çsbc2 & 30 & $18,8(3,2)$ & 12,6 & 24,2 & $529,4(217,7)$ & 267 & 1100 & $3,17(0,77)$ & 1,67 & 4,98 \\
\hline & Çsbc3 & 29 & $18,0(2,8)$ & 14,3 & 25,9 & $1064,7(365,1)$ & 500 & 1925 & $6,22(1,99)$ & 3,49 & 11,57 \\
\hline & Çsc1 & 8 & $27,2(4,5)$ & 17,6 & 32,3 & $302,3(132,3)$ & 133 & 463 & $3,30(1,53)$ & 1,62 & 5,70 \\
\hline & Çsc2 & 20 & $26,8(3,5)$ & 21,7 & 32,3 & $364,1(106,4)$ & 175 & 525 & $4,03(1,50)$ & 1,47 & 7,10 \\
\hline & Çsc3 & 30 & $23,0(3,5)$ & 16,0 & 31,0 & $730,0(177,9)$ & 475 & 1125 & $6,23(1,58)$ & 3,01 & 9,59 \\
\hline & Çscd1 & 29 & $30,2(5,1)$ & 19,5 & 39,6 & $229,1(56,9)$ & 138 & 383 & $2,91(0,74)$ & 1,81 & 5,04 \\
\hline & Çscd2 & 30 & $30,4(4,5)$ & 19,7 & 38,5 & $374,3(111,2)$ & 200 & 717 & $4,81(1,30)$ & 2,56 & 8,74 \\
\hline & Çscd3 & 30 & $31,2(5,7)$ & 21,2 & 42,4 & $645,8(227,2)$ & 275 & 1175 & $8,36(1,95)$ & 4,67 & 11,82 \\
\hline & Çsd1 & 17 & $48,2(15,1)$ & 34,2 & 85,3 & $137,5(62,0)$ & 63 & 300 & $3,32(1,31)$ & 1,78 & 6,96 \\
\hline & Çsd2 & 27 & $38,3(4,8)$ & 30,7 & 48,0 & $284,6(106,2)$ & 138 & 675 & $5,14(1,56)$ & 2,34 & 9,71 \\
\hline & Çsd3 & 7 & $39,5(7,0)$ & 32,9 & 53,4 & $395,3(105,4)$ & 183 & 500 & $7,42(1,78)$ & 5,61 & 10,00 \\
\hline
\end{tabular}

$\mathrm{Bu}$ çalışmada, Kastamonu yöresi saf sarıçam meşcerelerine ilişkin çap dağılımlarını modellemek üzere Beta, Gamma, Johnson SB, Log-normal, Normal ve Weibull dağılımlarına ilişkin olasılık yoğunluk fonksiyonlarından yararlanılmıştır. Bu fonksiyonlardan Gamma, Log-normal ve Weibull dağılımlarının parametre sayılarına bağlı olarak ikişer farklı formu dikkate alınmış ve böylelikle toplamda dokuz adet olasılık yoğunluk fonksiyonu geliştirilmeye çalışılmıştır. Çalışmada kullanılan olasılık yoğunluk fonksiyonları Tablo 2'de verilmiştir. Bu fonksiyonlara ilişkin parametre tahminleri, parametre tahmin yöntemi olarak Maksimum Olabilirlik Yöntemini kullanan EasyFit 5.5 Professional yazılımı yardımıyla yapılmıştır (Mathwave, 2015). Bu yazılım, herhangi bir çalışmaya ilişkin veri setinin dağılımını modellemek üzere seçilen olasılık yoğunluk fonksiyonlarının parametrelerini tahmin etmektedir. 
Tablo 2. Çalışmada kullanılan olasılık yoğunluk fonksiyonları.

\begin{tabular}{|c|c|c|}
\hline Dağılım & Olasılık Yoğunluk Fonksiyonu & Açıklama \\
\hline $\begin{array}{l}\text { Beta } \\
\text { (Clutter ve Bennet, 1965) }\end{array}$ & $f(x)=\frac{1}{B\left(\alpha_{1}, \alpha_{2}\right)} \frac{(x-a)^{\alpha_{1}-1}(b-x)^{\alpha_{2}-1}}{(b-a)^{\alpha_{1}+\alpha_{2}-1}}$ & $\begin{array}{l}\alpha_{1}, \alpha_{2}, a, b \text { : Parametreler } \\
B\left(\alpha_{1}, \alpha_{2}\right): \text { Beta fonksiyonu } \\
a \leq x \leq b, \alpha_{1}>0, \alpha_{2}>0\end{array}$ \\
\hline $\begin{array}{l}\text { Gamma-2p } \\
\text { (Nelson, 1964) }\end{array}$ & $f(x)=\frac{x^{\alpha-1}}{\beta^{\alpha} \Gamma(\alpha)} e^{\left(\frac{-x}{\beta}\right)}$ & $\begin{array}{l}\alpha, \beta \text { : Parametreler } \\
\Gamma(\alpha): \text { Gamma fonksiyonu } \\
\alpha>0, \beta>0\end{array}$ \\
\hline $\begin{array}{l}\text { Gamma-3p } \\
\text { (Lawless, 1982) }\end{array}$ & $f(x)=\frac{(x-\gamma)^{\alpha-1}}{\beta^{\alpha} \Gamma(\alpha)} e^{\left(\frac{-(x-\gamma)}{\beta}\right)}$ & $\begin{array}{l}\alpha, \beta, \gamma \text { : Parametreler } \\
\Gamma(\alpha) \text { : Gamma fonksiyonu } \\
\alpha>0, \beta>0, \gamma \leq x \leq+\infty\end{array}$ \\
\hline $\begin{array}{l}\text { Johnson SB } \\
\text { (Johnson, 1949) }\end{array}$ & $f(x)=\frac{\delta}{\lambda \sqrt{2 \pi} z(1-z)} \mathrm{e}^{\left(-\frac{1}{2}\left(\gamma+\delta \ln \left(\frac{z}{z-1}\right)\right)^{2}\right)}$ & $\begin{array}{l}\delta, \lambda, \gamma, \xi \text { : Parametreler } \\
z=\frac{x-\xi}{\lambda} \\
\xi \leq x \leq \xi+\lambda, \delta>0, \gamma>0\end{array}$ \\
\hline $\begin{array}{l}\text { Log-normal-2p } \\
\text { (Bliss ve Reinker, 1964) }\end{array}$ & $f(x)=\frac{1}{x \sigma \sqrt{2 \pi}} e^{\left(-\frac{1}{2}\left(\frac{\ln x-\mu}{\sigma}\right)^{2}\right)}$ & $\mu, \sigma$ : Parametreler \\
\hline $\begin{array}{l}\text { Log-normal-3p } \\
\text { (Bliss ve Reinker, 1964) }\end{array}$ & $f(x)=\frac{1}{(x-\gamma) \sigma \sqrt{2 \pi}} e^{\left(-\frac{1}{2}\left(\frac{\ln (x-\gamma)-\mu}{\sigma}\right)^{2}\right)}$ & $\begin{array}{l}\mu, \sigma, \gamma \text { : Parametreler } \\
\gamma \leq x \leq+\infty\end{array}$ \\
\hline $\begin{array}{l}\text { Normal } \\
\text { (Bailey, 1980) }\end{array}$ & $f(x)=\frac{1}{\sigma \sqrt{2 \pi}} \mathrm{e}^{\left(-\frac{1}{2}\left(\frac{x-\mu}{\sigma}\right)^{2}\right)}$ & $\mu, \sigma$ : Parametreler \\
\hline $\begin{array}{l}\text { Weibull-2p } \\
\text { (Schreuder ve Swank, 1974) }\end{array}$ & $f(x)=\frac{\alpha}{\beta}\left(\frac{x}{\beta}\right)^{\alpha-1} e^{\left(-\left(\frac{x}{\beta}\right)^{\alpha}\right)}$ & $\begin{array}{l}\alpha, \beta \text { : Parametreler } \\
\alpha>0, \beta>0\end{array}$ \\
\hline $\begin{array}{l}\text { Weibull-3p } \\
\text { (Bailey ve Dell, 1973) }\end{array}$ & $f(x)=\frac{\alpha}{\beta}\left(\frac{x-\gamma}{\beta}\right)^{\alpha-1} e^{\left(-\left(\frac{x-\gamma}{\beta}\right)^{\alpha}\right)}$ & $\begin{array}{l}\alpha, \beta, \gamma: \text { Parametreler } \\
\alpha>0, \beta>0, \gamma \leq x \leq+\infty\end{array}$ \\
\hline
\end{tabular}

Çalışma kapsamında kullanılacak verilerin analize hazır hale getirilmesinde öncelikle farklı örnek alan büyüklüklerine sahip tüm örnek alanlar standart birim alana (1 ha) dönüştürülmüştür. Söz konusu dönüștürme işleminde Hektara Çevirme Katsayısı $(H C ̧ K=10000 / O ̈ A B)$ değerlerinden yararlanılmıştır. Tüm örnek alanlar standart büyüklüğe dönüştürüldükten sonra, her bir örnek alanda bulunan ağaçlar göğüs çaplarına bağlı olarak 4 cm genişliğindeki $(8,0-11,9 \mathrm{~cm}, 12,0-15,9 \mathrm{~cm}, \ldots, 72,0-75,9 \mathrm{~cm}$ gibi) çap basamaklarına dağıtılmıştır.

Her bir örnek alan için parametre tahminleri yapılan olasılık yoğunluk fonksiyonlarının, ilgili örnek alana özgü çap dağılımına istatistiksel olarak uygunluğunun belirlenmesinde Kolmogorov-Smirnov (KS), Anderson-Darling $(A D)$ ve Ki-kare $\left(X^{2}\right)$ istatistiklerinden yararlanılmıştır. Kullanılan yazılım $K S, A D$ ve $X^{2}$ istatistiklerini doğrudan hesaplamakta ve olasılık yoğunluk fonksiyonlarını da bu istatistiklere göre ayrı ayrı sıralamaktadır. Dolayısıyla, bu istatistikler ve fonksiyonların her bir ölçüte göre başarı sıralamaları da EasyFit 5.5 Professional yazılımı ile elde edilmiştir. Ancak, söz konusu yazılım kimi durumlarda herhangi bir fonksiyonu çözümleyebilmesine karşın $K S, A D$ ve $X^{2}$ istatistiklerinden bazılarını hesaplayamamaktadır. Bu olumsuzluğun giderilebilmesi için ilave bir istatistiksel ölçüte ihtiyaç duyulmuş ve bu amaçla Reynolds vd. (1988) tarafından geliştirilen Hata İndeksi (e) ölçütünden yararlanılmıştır:

$$
e=\sum_{j=1}^{k}\left|N_{t}-N\right|
$$

$\mathrm{Bu}$ eşitlikte; $k$ örnek alandaki çap basamağı sayısını, $N$ örnek alanın temsil ettiği meşcerede $j$ 'inci çap basamağında ölçülen ağaç sayısını (adet/ha) ve $N_{t}$ örnek alanın temsil ettiği meşcerede $j$ 'inci çap basamağı için olasılık yoğunluk fonksiyonu ile tahmin edilen ağaç sayısını (adet/ha) ifade etmektedir.

Herhangi bir örnek alan için, olasılık yoğunluk fonksiyonlarının hata indeksi (e) değerlerine göre karşılaştırılmasında Poudel ve Cao (2013) tarafından önerilen rölatif sıralama yöntemi kullanılmıştır. Bu yöntem, fonksiyonları aşağıdaki eşitlik yardımıyla en başarılıdan en başarısıza doğru 1 ile $m$ arasında sıralamaktadır. Rölatif sırası 1 olan model en başarılı ve $m$ olan model de en başarısız model olurken, diğer modeller de 1 'den büyük $m$ 'den küçük rölatif değerler alarak sıralanmaktadır. 


$$
R_{i}=1+\frac{(m-1)\left(e_{i}-e_{\min }\right)}{\left(e_{\text {maks }}-e_{\min }\right)}
$$

$\mathrm{Bu}$ eşitlikte; $R_{i} i$. fonksiyona ilişkin rölatif sırayı, $e_{i} i$. fonksiyona ilişkin istatistiksel ölçüt değerini, $e_{\min }$ fonksiyonlar arasındaki en düşük $e_{i}$ değerini, $e_{\text {maks }}$ fonksiyonlar arasındaki en yüksek $e_{i}$ değerini ve $m$ karşılaştırılan fonksiyon sayısııı ifade etmektedir.

Yukarıda açıklanan istatistiksel ölçütler (KS, $A D, X^{2}$ ve $e$ ) yardımıyla her bir örnek alan için olasılık yoğunluk fonksiyonlarının başarı sıralamaları yapılmıştır. Fonksiyonların başarı sıralarının (1'den 9'a kadar) frekans dağılımları tablolaştırılarak fonksiyonların genel başarı eğilimleri belirlenmeye çalışılmıştır. Olasılık yoğunluk fonksiyonlarının başarı sıralamalarının meşceredeki ağaç sayısı, meşcere orta çapı ve sıklık derecesi bakımından farklılık gösterip göstermediğinin belirlenmesinde Kruskal-Wallis Testi'nden yararlanılmıştır. Bu testin uygulanmasında, örnek alanlar için $e$ ölçütüne göre en başarılı bulunan olasılık yoğunluk fonksiyonlarının frekans dağılımları gruplandırma faktörü ve ilgili örnek alana ilişkin sözü edilen meşcere özellikleri de bağımsız değişken olarak dikkate alınmıştır. Kruskal-Wallis Testi'ne göre anlamlı farklılıkların gözlemlenmesi durumunda gruplar arası ikili karşılaştırmalar Mann-Whitney U Testi ile yapılmıştır. Olasılık yoğunluk fonksiyonlarının başarı sıralamalarının bonitet sınıfı, kapalılık, gelişim çağı ve meşcere tipine göre değişiminin incelenmesinde ise Kikare $\left(X^{2}\right)$ Testi kullanılmıştır. Bu testin uygulanmasında da yine örnek alanlar için $e$ ölçütüne göre en başarılı bulunan olasılık yoğunluk fonksiyonlarının ilgilenilen meșcere özelliğine göre frekans dağılımlarından yararlanılmıştır. Çalışma kapsamında gerçekleştirilen istatistiksel analizler için Jamovi yazılımından yararlanılmıştır (The Jamovi Project, 2019).

İstatistiksel karşılaştırmalar sonucunda çeşitli meşcere özellikleri bakımından en başarılı bulunan olasılık yoğunluk fonksiyonlarının meşcere tiplerine göre tahmin davranışlarının ortaya konulması amacıyla her bir meşcere tipi için seçilen temsili örnek alanlardaki çap basamaklarına göre ölçülen ve ilgili olasılık yoğunluk fonksiyonu ile tahmin edilen ağaç sayılarının karşılaştırıldığı grafikler çizilmiş̧ir.

\section{Bulgular ve Tartışma}

Değerlendirilen 890 örnek alana ilişkin çap dağılımları Beta, Gamma-2p, Gamma-3p, Johnson SB, Log-normal2p, Log-normal-3p, Normal, Weibull-2p ve Weibull-3p olasılık yoğunluk fonksiyonları ile modellenerek fonksiyonlara ilişsin parametreler her bir örnek alan için ayrı ayrı belirlenmiştir. Kolmogorov-Smirnov (KS), Anderson-Darling $(A D)$ ve Ki-kare $\left(X^{2}\right)$ istatistiklerine göre de fonksiyonların başarı sıralamaları yapılmıştır. Olasılık yoğunluk fonksiyonlarının $K S, A D$ ve $X^{2}$ istatistiklerine göre başarı sıralamalarının (1 ile 9 arasında) frekans dağılımları Tablo 3'te verilmiştir. Tabloda görüleceği üzere en fazla sayıda 1. sırayı alan fonksiyon her üç istatistiksel ölçüt için de Johnson SB fonksiyonu olmuştur (KS için 400, $A D$ için 352 ve $X^{2}$ için 207 örnek alan). Ancak, 12 örnek alanda Beta, 63 örnek alanda Johnson SB ve 67 örnek alanda ise Weibull-3p fonksiyonu çözümlenememiştir. Ayrıca, 11 örnek alanda Beta, 42 örnek alanda Gamma-3p, 5 örnek alanda Johnson SB, 53 örnek alanda Log-normal-3p ve 44 örnek alanda Weibull-3p fonksiyonları için $K S$ ve $A D$ istatistikleri ve 216 örnek alanda Beta, 281 örnek alanda Gamma-3p, 205 örnek alanda Johnson SB, 168 örnek alanda Log-normal3p ve 281 örnek alanda Weibull-3p fonksiyonları için $X^{2}$ istatistiği hesaplanamamıştır.

$K S, A D$ ve $X^{2}$ istatistiklerinin bazı olasılık yoğunluk fonksiyonları için hesaplanamadığı örnek alanlarda bu fonksiyonlar sıralamaya dahil edilememiştir. Bu olumsuzluğu ortadan kaldırmak üzere her bir örnek alanda parametreleri çözümlenebilen fonksiyonlara ilişkin hata indeksi $(e)$ değerleri hesaplanmış ve bu değerler yardımıyla olasılık yoğunluk fonksiyonlarının rölatif sıraları $\left(R_{i}\right)$ belirlenmiştir. Hesaplanan $R_{i}$ değerleri rölatif sıralamaları ifade ettiğinden bu değerlere ilişkin frekans tablosu oluşturmak mümkün olmamıştır.

Her bir örnek alan için modellenen olasılık yoğunluk fonksiyonlarının dört farklı istatistiksel ölçüte (KS, $A D, X^{2}$ ve $e$ ) göre başarı sıralamalarının örnek alan bazında münferit olarak değerlendirilmesi fonksiyonların genel başarıları hakkında fikir veremeyeceğinden, her bir fonksiyonun kullanılan istatistiksel ölçütler bakımından örnek alanlara ilişkin sıralamalarının ortalamaları hesaplanmıştır (Tablo 4, Şekil 1). Elde edilen sonuçlara göre tüm ölçütler için genel başarısı en yüksek olan fonksiyon Johnson SB olurken, en başarısız fonksiyonlar ise $K S$ ve $e$ istatistikleri için Gamma-3p fonksiyonu, $A D$ ve $X^{2}$ istatistikleri için ise Beta fonksiyonu olmuştur. 
Tablo 3. Olasılık yoğunluk fonksiyonlarının $K S, A D$ ve $X^{2}$ ölçütlerine göre sıralamalarının frekans dağılımları.

\begin{tabular}{|c|c|c|c|c|c|c|c|c|c|c|}
\hline \multirow[b]{2}{*}{$\begin{array}{l}\text { İstatistiksel } \\
\text { Ölçüt }\end{array}$} & \multirow[b]{2}{*}{ Siralama } & \multicolumn{9}{|c|}{ Olasılık Yoğunluk Fonksiyonu } \\
\hline & & $\stackrel{\pi}{0}$ & 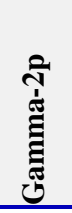 & 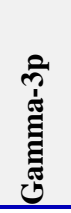 & 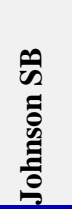 & 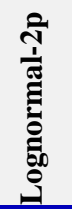 & 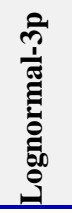 & 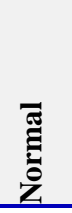 & 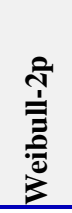 & 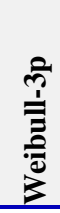 \\
\hline \multirow{10}{*}{$\begin{array}{l}\text { Kolmogorov- } \\
\text { Smirnov } \\
(K S)\end{array}$} & 1 & 59 & 82 & 33 & 400 & 42 & 47 & 52 & 91 & 84 \\
\hline & 2 & 97 & 83 & 39 & 162 & 59 & 73 & 95 & 191 & 91 \\
\hline & 3 & 66 & 87 & 49 & 103 & 72 & 115 & 184 & 146 & 68 \\
\hline & 4 & 61 & 118 & 74 & 53 & 103 & 135 & 182 & 89 & 75 \\
\hline & 5 & 58 & 92 & 98 & 56 & 136 & 164 & 118 & 86 & 81 \\
\hline & 6 & 122 & 116 & 146 & 26 & 77 & 96 & 94 & 82 & 124 \\
\hline & 7 & 160 & 152 & 99 & 8 & 110 & 63 & 72 & 88 & 108 \\
\hline & 8 & 110 & 128 & 106 & 7 & 158 & 43 & 69 & 81 & 123 \\
\hline & 9 & 134 & 32 & 204 & 7 & 133 & 101 & 24 & 36 & 25 \\
\hline & Hesaplanamayan & 11 & - & 42 & 5 & - & 53 & - & - & 44 \\
\hline \multirow{10}{*}{$\begin{array}{l}\text { Anderson- } \\
\text { Darling } \\
\text { (AD) }\end{array}$} & 1 & 15 & 78 & 22 & 352 & 45 & 58 & 60 & 191 & 69 \\
\hline & 2 & 28 & 159 & 40 & 116 & 64 & 92 & 140 & 195 & 56 \\
\hline & 3 & 22 & 82 & 75 & 67 & 125 & 121 & 240 & 93 & 65 \\
\hline & 4 & 12 & 90 & 98 & 34 & 97 & 208 & 208 & 102 & 41 \\
\hline & 5 & 33 & 116 & 132 & 68 & 148 & 114 & 107 & 99 & 72 \\
\hline & 6 & 117 & 99 & 123 & 44 & 104 & 90 & 52 & 100 & 154 \\
\hline & 7 & 115 & 196 & 92 & 49 & 101 & 50 & 55 & 38 & 164 \\
\hline & 8 & 182 & 66 & 91 & 62 & 178 & 52 & 28 & 51 & 115 \\
\hline & 9 & 343 & 4 & 175 & 30 & 28 & 52 & - & 21 & 43 \\
\hline & Hesaplanamayan & 11 & - & 42 & 5 & - & 53 & - & - & 44 \\
\hline \multirow{10}{*}{$\begin{array}{l}\text { Ki-kare } \\
\left(X^{2}\right)\end{array}$} & 1 & 75 & 131 & 31 & 207 & 98 & 59 & 107 & 92 & 90 \\
\hline & 2 & 52 & 155 & 59 & 114 & 97 & 118 & 124 & 100 & 71 \\
\hline & 3 & 44 & 138 & 94 & 65 & 116 & 101 & 137 & 139 & 56 \\
\hline & 4 & 40 & 116 & 96 & 56 & 124 & 107 & 170 & 110 & 71 \\
\hline & 5 & 80 & 101 & 86 & 55 & 157 & 122 & 113 & 127 & 47 \\
\hline & 6 & 164 & 102 & 89 & 43 & 106 & 110 & 74 & 89 & 69 \\
\hline & 7 & 103 & 82 & 85 & 42 & 89 & 63 & 89 & 86 & 74 \\
\hline & 8 & 54 & 51 & 53 & 27 & 73 & 34 & 51 & 102 & 47 \\
\hline & 9 & 50 & 14 & 16 & 13 & 30 & 8 & 25 & 45 & 17 \\
\hline & Hesaplanamayan & 216 & - & 281 & 205 & - & 168 & - & - & 281 \\
\hline \multicolumn{2}{|c|}{ Çözümsüz } & 12 & - & - & 63 & - & - & - & - & 67 \\
\hline
\end{tabular}

Tablo 4. Olasılık yoğunluk fonksiyonlarının başarı sırası ortalamaları.

\begin{tabular}{|c|c|c|c|c|c|c|c|c|c|}
\hline \multirow[b]{2}{*}{ İstatistiksel Ölçüt } & \multicolumn{8}{|c|}{ Olasılık Yoğunluk Fonksiyonu } & \multirow[b]{2}{*}{ 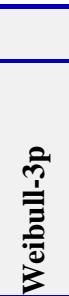 } \\
\hline & ڤేّ & 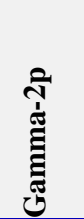 & 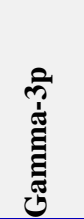 & 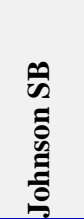 & 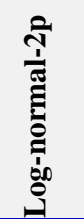 & 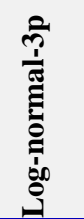 & $\begin{array}{l}\text { 펼 } \\
\text { हे }\end{array}$ & 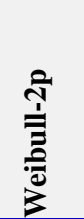 & \\
\hline Kolmogorov-Smirnov (KS) & 5,68 & 5,07 & 6,25 & 2,26 & 5,80 & 4,98 & 4,44 & 4,24 & 4,99 \\
\hline Anderson-Darling (AD) & 7,38 & 4,62 & 5,97 & 3,20 & 5,26 & 4,52 & 3,76 & 3,62 & 5,49 \\
\hline Ki-kare $\left(X^{2}\right)$ & 5,22 & 3,98 & 4,83 & 3,24 & 4,53 & 4,27 & 4,17 & 4,65 & 4,39 \\
\hline Hata İndeksi $(e)$ & 4,33 & 4,44 & 5,03 & 1,75 & 4,97 & 4,49 & 3,80 & 3,77 & 3,97 \\
\hline
\end{tabular}




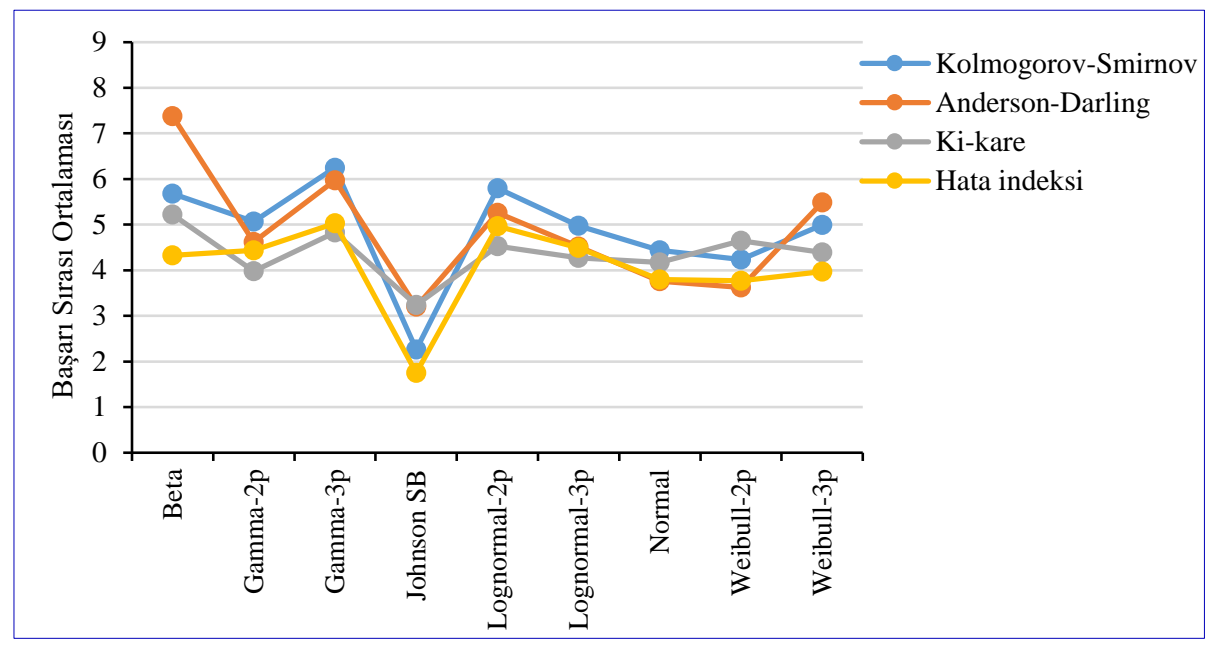

Şekil 1. Olasılık yoğunluk fonksiyonlarının istatistiksel ölçütlere göre başarı durumları.

Olasılık yoğunluk fonksiyonlarının $e$ istatistiğine göre en başarılı bulunma durumlarının ağaç sayısı, orta çap ve sıklık derecesi ile ilişkileri Kruskal-Wallis testiyle belirlenmiştir. Test sonuçlarına göre fonksiyonların en başarılı olma durumları ağaç sayısı ve orta çap değerlerinden etkilenmekte iken $(p<0,05)$, sıklık derecesinin etkili olmadığı $(p>0,05)$ görülmüş̧tür (Tablo 5). Sonuçlar ağaç sayısı için irdelendiğinde; Beta, Gamma-3p, Normal, Weibull-2p ve Weibull-3p fonksiyonlarının ağaç sayısının düşük olduğu, Gamma-2p, Johnson SB ve Lognormal-3p fonksiyonlarının ağaç sayısının kısmen daha yüksek olduğu ve Log-normal-2p fonksiyonunun da ağaç sayısının yüksek olduğu meşcerelerde daha başarılı olduğu anlaşılmaktadır. Orta çap bakımından ise; Gamma2p, Gamma-3p ve Log-normal-2p fonksiyonlarının orta çapın düşük olduğu, Johnson SB ve Log-normal-3p fonksiyonlarının orta çapın kısmen daha yüksek olduğu ve Beta, Normal, Weibull-2p ve Weibull-3p fonksiyonlarının ise meşcere orta çapının yüksek olduğu meşcerelerde daha başarılı olduğu görülmüştür.

Tablo 5. En başarılı fonksiyonların frekans dağılımlarına ilişkin Kruskal-Wallis Testi sonuçları.

\begin{tabular}{|c|c|c|c|c|c|c|c|c|}
\hline $\begin{array}{l}\text { Meşcere } \\
\text { Özelliği }\end{array}$ & $\begin{array}{l}\text { Olasılık Yoğunluk } \\
\text { Fonksiyonu }\end{array}$ & $\bar{n}$ & Minimum & Maksimum & Ortalama & $\begin{array}{c}\text { Homojen } \\
\text { Gruplar }\end{array}$ & $\begin{array}{l}\text { Standart } \\
\text { Sapma }\end{array}$ & $\bar{p}$ \\
\hline $\begin{array}{l}\text { Ağaç sayısı } \\
\text { (adet/ha) }\end{array}$ & $\begin{array}{l}\text { Beta } \\
\text { Gamma-2p } \\
\text { Gamma-3p } \\
\text { Johnson SB } \\
\text { Log-normal-2p } \\
\text { Log-normal-3p } \\
\text { Normal } \\
\text { Weibull-2p } \\
\text { Weibull-3p }\end{array}$ & $\begin{array}{c}108 \\
33 \\
22 \\
388 \\
57 \\
64 \\
78 \\
69 \\
71\end{array}$ & $\begin{array}{c}63 \\
150 \\
233 \\
50 \\
213 \\
100 \\
50 \\
100 \\
113\end{array}$ & $\begin{array}{l}1700 \\
2250 \\
1325 \\
3450 \\
2600 \\
1800 \\
2450 \\
1425 \\
1750\end{array}$ & $\begin{array}{l}418,0 \\
796,5 \\
551,0 \\
601,4 \\
931,3 \\
653,2 \\
545,8 \\
490,8 \\
497,3\end{array}$ & $\begin{array}{c}\mathrm{c} \\
\mathrm{ab} \\
\mathrm{bc} \\
\mathrm{b} \\
\mathrm{a} \\
\mathrm{ab} \\
\mathrm{bc} \\
\mathrm{bc} \\
\mathrm{bc}\end{array}$ & \begin{tabular}{l|}
278,8 \\
540,6 \\
321,4 \\
416,2 \\
567,6 \\
442,8 \\
357,7 \\
297,3 \\
308,8
\end{tabular} & $<0,001$ \\
\hline $\begin{array}{l}\text { Orta çap } \\
\text { (cm) }\end{array}$ & $\begin{array}{l}\text { Beta } \\
\text { Gamma-2p } \\
\text { Gamma-3p } \\
\text { Johnson SB } \\
\text { Log-normal-2p } \\
\text { Log-normal-3p } \\
\text { Normal } \\
\text { Weibull-2p } \\
\text { Weibull-3p }\end{array}$ & $\begin{array}{c}108 \\
33 \\
22 \\
388 \\
57 \\
64 \\
78 \\
69 \\
71\end{array}$ & $\begin{array}{c}15,1 \\
9,7 \\
12,7 \\
10,2 \\
10,0 \\
14,1 \\
11,4 \\
14,1 \\
14,2\end{array}$ & $\begin{array}{l}70,3 \\
48,7 \\
35,4 \\
55,4 \\
41,3 \\
47,5 \\
62,6 \\
60,4 \\
85,3\end{array}$ & $\begin{array}{l}31,7 \\
23,1 \\
22,4 \\
25,4 \\
19,3 \\
24,2 \\
28,8 \\
29,5 \\
28,7\end{array}$ & $\begin{array}{c}\mathrm{a} \\
\mathrm{bc} \\
\mathrm{bc} \\
\mathrm{b} \\
\mathrm{c} \\
\mathrm{b} \\
\mathrm{a} \\
\mathrm{a} \\
\mathrm{ab}\end{array}$ & $\begin{array}{c}9,2 \\
9,9 \\
6,3 \\
9,8 \\
8,1 \\
8,0 \\
9,1 \\
10,6 \\
10,3\end{array}$ & $<0,001$ \\
\hline $\begin{array}{l}\text { Siklık } \\
\text { derecesi }\end{array}$ & $\begin{array}{l}\text { Beta } \\
\text { Gamma-2p } \\
\text { Gamma-3p } \\
\text { Johnson SB } \\
\text { Log-normal-2p } \\
\text { Log-normal-3p } \\
\text { Normal } \\
\text { Weibull-2p } \\
\text { Weibull-3p }\end{array}$ & $\begin{array}{c}108 \\
33 \\
22 \\
388 \\
57 \\
64 \\
78 \\
69 \\
71\end{array}$ & $\begin{array}{l}1,04 \\
0,79 \\
1,24 \\
0,84 \\
1,24 \\
1,00 \\
1,07 \\
1,08 \\
1,45\end{array}$ & $\begin{array}{c}11,44 \\
11,16 \\
9,34 \\
14,67 \\
10,40 \\
11,16 \\
12,97 \\
11,57 \\
14,38\end{array}$ & $\begin{array}{l}5,51 \\
5,37 \\
4,38 \\
4,82 \\
4,79 \\
5,29 \\
5,23 \\
5,19 \\
5,23\end{array}$ & $\begin{array}{l}- \\
- \\
- \\
- \\
- \\
- \\
- \\
- \\
-\end{array}$ & $\begin{array}{l}2,41 \\
2,46 \\
2,10 \\
2,16 \\
2,12 \\
2,35 \\
2,57 \\
2,70 \\
2,64\end{array}$ & 0,228 \\
\hline
\end{tabular}


Olasılık yoğunluk fonksiyonlarının $e$ istatistiğine göre en başarılı bulunma durumlarının bonitet sınıfı, kapalılık, gelişim çağı ve meşcere tipi özelliklerine göre değişiminin belirlenmesinde Ki-kare $\left(X^{2}\right)$ Testi kullanılmıştır. Sonuçlar, fonksiyonların en başarılı bulunma durumlarının kapalılık sınıfı, gelişim çağı ve meşcere tipinden etkilendiğini $(p<0,05)$, bonitet sınıfından ise etkilenmediğini $(p>0,05)$ göstermiştir (Tablo 6).

Tablo 6. En başarılı fonksiyonların frekans dağılımlarına ilişkin Ki-kare $\left(X^{2}\right)$ Testi sonuçları.

\begin{tabular}{|c|c|c|c|c|c|c|c|c|c|c|c|c|}
\hline \multirow{2}{*}{\multicolumn{2}{|c|}{ Meşcere Özelliği }} & & \multicolumn{9}{|c|}{ Olasılık Yoğunluk Fonksiyonu } & \multirow[b]{2}{*}{$p$} \\
\hline & & & 营 & \multirow[t]{2}{*}{ 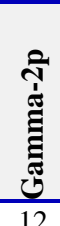 } & 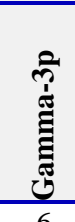 & 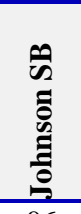 & 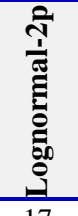 & 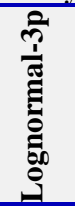 & 를 & \multirow[t]{2}{*}{ 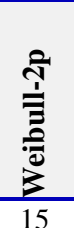 } & 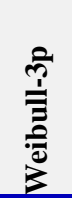 & \\
\hline Bonitet Sinıfı & I $(26,5-32,5 \mathrm{~m})$ & $\mathrm{n}$ & 33 & & 6 & $\begin{array}{c}96 \\
395\end{array}$ & 17 & 19 & 23 & & 22 & 0,219 \\
\hline & & $\%$ & $\begin{array}{c}13,6 \\
37\end{array}$ & $\begin{array}{r}4,9 \\
13\end{array}$ & $\begin{array}{c}2,5 \\
4\end{array}$ & $\begin{array}{l}39,5 \\
144\end{array}$ & $\begin{array}{l}7,0 \\
18\end{array}$ & $\begin{array}{l}7,8 \\
20\end{array}$ & $\begin{array}{l}9,5 \\
27\end{array}$ & $\begin{array}{l}6,2 \\
26\end{array}$ & $\begin{array}{l}9,1 \\
35\end{array}$ & \\
\hline & $11(20,5-20,5 \mathrm{~m})$ & $\%$ & 11,4 & 4,0 & 1,2 & 44,4 & 5,6 & 6,2 & 8,3 & 8,0 & 10,8 & \\
\hline & III (14,5-20,5 m) & $\mathrm{n}$ & 38 & 8 & 12 & 148 & 22 & 25 & 28 & 28 & 14 & \\
\hline & & $\%$ & 11,8 & 2,5 & 3,7 & 45,8 & 6,8 & 7,7 & 8,7 & 8,7 & 4,3 & \\
\hline Kapalılık & $1(\% 11-40)$ & $\mathrm{n}$ & 27 & 3 & 8 & 73 & 8 & 13 & 12 & 13 & 17 & 0,009 \\
\hline & & $\%$ & 15,5 & 1,7 & 4,6 & 42,0 & 4,6 & 7,5 & 6,9 & 7,5 & 9,8 & \\
\hline & $2(\% 41-70)$ & $\mathrm{n}$ & 39 & 11 & 6 & 149 & 8 & 19 & 31 & 22 & 26 & \\
\hline & & $\%$ & 12,5 & 3,5 & 1,9 & 47,9 & 2,6 & 6,1 & 10,0 & 7,1 & 8,4 & \\
\hline & $3(>\% 70)$ & $\mathrm{n}$ & 42 & 19 & 8 & 166 & 41 & 32 & 35 & 34 & 28 & \\
\hline & & $\%$ & 10,4 & 4,7 & 2,0 & 41,0 & 10,1 & 7,9 & 8,6 & 8,4 & 6,9 & \\
\hline Gelişim Çağı & $\mathrm{b}$ & $\mathrm{n}$ & 1 & 9 & 2 & 50 & 24 & 9 & 6 & 4 & 4 & $<0,001$ \\
\hline & & $\%$ & 0,9 & 8,3 & 1,8 & 45,9 & 22,0 & 8,3 & 5,5 & 3,7 & 3,7 & \\
\hline & bc & $\mathrm{n}$ & 6 & 7 & 6 & 98 & 11 & 22 & 8 & 13 & 10 & \\
\hline & & $\%$ & 3,3 & 3,9 & 3,3 & 54,1 & 6,1 & 12,2 & 4,4 & 7,2 & 5,5 & \\
\hline & $\mathrm{C}$ & $\mathrm{n}$ & 27 & 3 & 6 & 68 & 6 & 8 & 20 & 18 & 17 & \\
\hline & & $\%$ & 15,6 & 1,7 & 3,5 & 39,3 & 3,5 & 4,6 & 11,6 & 10,4 & 9,8 & \\
\hline & $\mathrm{cd}$ & $\mathrm{n}$ & 43 & 8 & 7 & 99 & 14 & 16 & 25 & 17 & 20 & \\
\hline & & $\%$ & 17,3 & 3,2 & 2,8 & 39,8 & 5,6 & 6,4 & 10,0 & 6,8 & 8,0 & \\
\hline & $\mathrm{d}$ & $\mathrm{n}$ & 31 & 6 & 1 & 73 & 2 & 9 & 19 & 17 & 20 & \\
\hline & & $\%$ & 17,4 & 3,4 & 0,6 & 41,0 & 1,1 & 5,1 & 10,7 & 9,6 & 11,2 & \\
\hline Meşcere Tipi & Çsb1 & $\mathrm{n}$ & - & - & - & 3 & 2 & - & - & - & - & $<0,001$ \\
\hline & & $\%$ & - & - & - & 60,0 & 40,0 & - & - & - & - & \\
\hline & Çsb2 & $\mathrm{n}$ & - & 1 & - & 7 & 1 & 2 & 1 & 1 & 1 & \\
\hline & & $\%$ & - & 7,1 & - & 50,0 & 7,1 & 14,3 & 7,1 & 7,1 & 7,1 & \\
\hline & Çsb3 & $\mathrm{n}$ & 1 & 8 & 2 & 40 & 21 & 7 & 5 & 3 & 3 & \\
\hline & & $\%$ & 1,1 & 8,9 & 2,2 & 44,4 & 23,3 & 7,8 & 5,6 & 3,3 & 3,3 & \\
\hline & Çsbc1 & $\mathrm{n}$ & 1 & 2 & 2 & 17 & - & 7 & - & 2 & 3 & \\
\hline & & $\%$ & 2,9 & 5,9 & 5,9 & 50,0 & - & 20,6 & - & 5,9 & 8,8 & \\
\hline & Çsbc2 & $\mathrm{n}$ & - & 1 & 3 & 38 & 2 & 3 & 6 & 3 & 2 & \\
\hline & & $\%$ & - & 1,7 & 5,2 & 65,5 & 3,4 & 5,2 & 10,3 & 5,2 & 3,4 & \\
\hline & Çsbc3 & $\mathrm{n}$ & 5 & 4 & 1 & 43 & 9 & 12 & 2 & 8 & 5 & \\
\hline & & $\%$ & 5,6 & 4,5 & 1,1 & 48,3 & 10,1 & 13,5 & 2,2 & 9,0 & 5,6 & \\
\hline & Çsc1 & $\mathrm{n}$ & 1 & - & 2 & 6 & - & 1 & 1 & 2 & 3 & \\
\hline & & $\%$ & 6,3 & - & 12,5 & 37,5 & - & 6,3 & 6,3 & 12,5 & 18,8 & \\
\hline & Çsc2 & $\mathrm{n}$ & 11 & 2 & 2 & 29 & - & 4 & 5 & 7 & 7 & \\
\hline & & $\%$ & 16,4 & 3,0 & 3,0 & 43,3 & - & 6,0 & 7,5 & 10,4 & 10,4 & \\
\hline & Çsc3 & $\mathrm{n}$ & 15 & 1 & 2 & 33 & 6 & 3 & 14 & 9 & 7 & \\
\hline & & $\%$ & 16,7 & 1,1 & 2,2 & 36,7 & 6,7 & 3,3 & 15,6 & 10,0 & 7,8 & \\
\hline & Çscd1 & $\mathrm{n}$ & 13 & - & 4 & 27 & 6 & 2 & 8 & 3 & 6 & \\
\hline & & $\%$ & 18,8 & - & 5,8 & 39,1 & 8,7 & 2,9 & 11,6 & 4,3 & 8,7 & \\
\hline & Çscd2 & $\mathrm{n}$ & 15 & 3 & - & 40 & 3 & 6 & 11 & 3 & 9 & \\
\hline & & $\%$ & 16,7 & 3,3 & - & 44,4 & 3,3 & 6,7 & 12,2 & 3,3 & 10,0 & \\
\hline & Çscd3 & $\mathrm{n}$ & 15 & 5 & 3 & 32 & 5 & 8 & 6 & 11 & 5 & \\
\hline & & $\%$ & 16,7 & 5,6 & 3,3 & 35,6 & 5,6 & 8,9 & 6,7 & 12,2 & 5,6 & \\
\hline & Çsd1 & $\mathrm{n}$ & 12 & 1 & - & 20 & - & 3 & 3 & 6 & 5 & \\
\hline & & $\%$ & 24,0 & 2,0 & - & 40,0 & - & 6,0 & 6,0 & 12,0 & 10,0 & \\
\hline & Çsd2 & $\mathrm{n}$ & 13 & 4 & 1 & 35 & 2 & 4 & 8 & 8 & 7 & \\
\hline & & $\%$ & 15,9 & 4,9 & 1,2 & 42,7 & 2,4 & 4,9 & 9,8 & 9,8 & 8,5 & \\
\hline & Çsd3 & $\mathrm{n}$ & 6 & 1 & - & 18 & - & 2 & 8 & 3 & 8 & \\
\hline & & $\%$ & 13,0 & 2,2 & - & 39,1 & - & 4,3 & 17,4 & 6,5 & 17,4 & \\
\hline
\end{tabular}


Tablo 6 incelendiğinde, her üç kapalılık sınıfı için de en fazla sayıda en başarılı bulunan olasılık yoğunluk fonksiyonunun Johnson SB fonksiyonu olduğu ve bu fonksiyonu Beta fonksiyonunun izlediği görülmektedir. Diğer fonksiyonların en başarılı bulunma sayıları ise daha düşük değerler almıştır. Sonuçlar gelişim çağları bakımından değerlendirildiğinde, tüm gelişim çağları için yine en fazla sayıda 1. sırayı alan fonksiyon Johnson SB fonksiyonu olmuş ve bu fonksiyonu b çağında Log-normal-2p, bc çağında Log-normal-3p ve c, cd ve d çağlarında ise Beta fonksiyonları izlemiştir. Meşcere tipleri için yapılan değerlendirmede de yine tüm meşcere tipleri için en fazla sayıda en başarılı bulunan fonksiyon Johnson SB fonksiyonu olmuş, diğer fonksiyonların en başarılı bulunma sayıları ise daha düşük değerler almıştır.

Elde edilen bulgular, Kastamonu yöresi saf sarıçam meşcerelerinin çap dağılımlarının modellenmesinde en başarılı olasılık yoğunluk fonksiyonunun Johnson SB fonksiyonu olduğunu göstermektedir. Bu fonksiyonun başarısını görsel olarak ortaya koyabilmek için örnek alanlardaki çap basamakları için bu fonksiyon yardımıyla hesaplanan tahmini ağaç sayıları ile gerçek ağaç sayılarını karşılaştırmak üzere c çağındaki meşcereler baz alınarak farklı bonitet sınıfları ve meşcere tipleri için dağılım grafikleri çizilmiştir (Şekil 2). Bu grafikler için meşcere tiplerini temsil edecek örnek alanlar belirlenmiş olup, bu örnek alanların seçiminde ilgili örnek alan için en başarılı olarak belirlenen fonksiyonun Johnson SB fonksiyonu olmasına dikkat edilmiştir. Grafikler incelendiğinde, örnek alanlarda ölçülen çap değerlerinin $4 \mathrm{~cm}$ 'lik çap basamaklarına dağılımları ile her bir çap basamağ için Johnson SB fonksiyonu ile hesaplanan dağılımların birbirlerine benzerlik gösterdiği görülmektedir. İstatistiksel analizlerin yanında görsel olarak da ortaya konan bu durum, Kastamonu yöresi saf sarıçam meşcerelerinin çap dağılımlarının modellenmesi için Johnson SB dağılımının uygun olduğunu desteklemektedir. Fonseca vd. (2009), Johnson SB fonksiyonunun çap dağılımı gibi biyolojik değişkenlerin açılanmasında gösterdiği bu başarının (i) dağılımı modellenen toplum özelliğinin alt ve üst sınırlarının modelde yer alması ve (ii) iki biçim parametresi ( $\delta$ ve $\gamma$ ) içermesi nedeniyle daha esnek tahminler sunabilmesi şeklinde iki nedenle açıklanabileceğini ifade etmiştir.

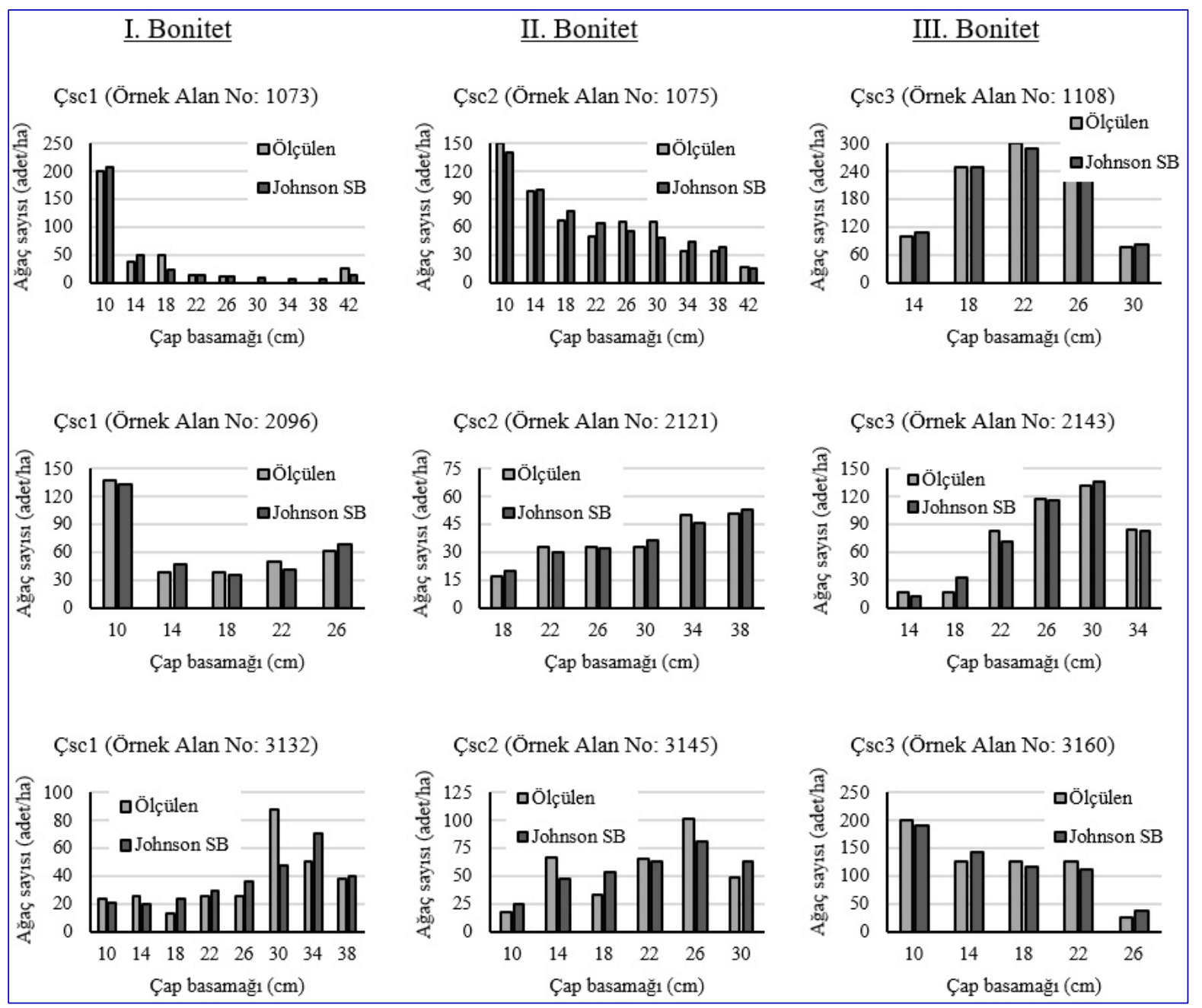

Şekil 2. Johnson SB fonksiyonu ile elde edilen tahminlere ilişkin karşılaştırma grafikleri. 
Literatürde çeşitli ağaç türlerinin çap dağılımlarının modellenmesi amacıyla farklı olasılık yoğunluk fonksiyonlarının karşılaştırıldığı çalışmalar bulunmaktadır. Kastamonu ili saf sarıçam meşcerelerinin çap dağılımlarının modellenmesi ve meşcere özellikleri bakımından karşılaştırılması amacıyla yapılan bu çalışmada elde edilen bulguların literatürdeki diğer araştırmalarla karşılaştırılmasına ilişkin bilgiler aşağıda verilmiştir.

Hafley ve Schreuder (1977) tarafından Amerika Birleşik Devletleri’ndeki Pinus taeda, Pinus palustris ve Pinus echinata meşcerelerinin çap dağılımlarını modellemek üzere yapılan bir çalışmada Beta, Gamma, Johnson SB, Normal, Log-normal ve Weibull fonksiyonları, Kamziah vd. (2000) tarafından Malezya'daki çeşitli ağaç türleri için yürütülen bir çalışmada Gamma, Johnson SB, Normal, Log-normal ve Weibull fonksiyonları, Chen (2004) tarafından Kanada'daki farklı orman yapılarının biyokütle tahmin modellerinde kullanılacak çap dağılım fonksiyonlarının geliştirilmesi amacıyla yapılan bir diğer araştırmada Johnson SB, Log-normal ve Weibull fonksiyonları ve Khongor vd. (2011) tarafından Moğolistan'daki Larix sibirica meşcereleri için yapılan bir başka araştırmada da Burr, Johnson SB ve Weibull fonksiyonları karşılaştırılmıştır. Bu araştırmaların tamamında, istatistiksel karşılaştırmalar sonucunda Johnson SB fonksiyonu en başarılı fonksiyon olarak belirlenmiştir. Amerika Birleşik Devletleri’ndeki Pinus taeda ağaçlandırmalarının çap dağılımlarının modellenmesi amacıyla Gamma, Johnson SB, Normal, Log-normal ve Weibull fonksiyonlarının ve Brezilya'nın farklı orman formlarındaki çap dağılımlarının modellenmesi için Beta, Birnbaum-Saunders, Gamma, Johnson SB, Logitlojistik, Log-normal, Üstel ve Weibull fonksiyonlarının karşılaştırıldığı araştırmalarda ise Weibull fonksiyonu başarılı bulunmuştur (Bullock ve Burkhart, 2005; Lima vd., 2014). Kastamonu yöresi sarıçam meşcerelerinde yürütülen bu çalışmada en başarılı bulunan olasılık yoğunluk fonksiyonunun Johnson SB olduğu ve ikinci sırayı da Weibull-2p fonksiyonunun aldığı dikkate alınırsa, yukarıda açıklanan araştırmalara ilişkin sonuçların bu çalışmanın sonuçları ile benzerlik gösterdiği söylenebilir. Bir başka ifadeyle, bu çalışma sonucunda elde edilen bulgular literatürdeki diğer birçok araştırmanın sonuçları ile uyum içerisindedir. Gorgoso vd. (2012) tarafından İspanya'da yürütülen bir araştırmada da Pinus pinaster, Pinus radiata ve Pinus sylvestris meşcerelerinin çap dağılımları modellenmeye çalışılmış ve bu amaçla Beta, Johnson SB ve Weibull dağılımları karşılaştırılmıştır. Çalışmada incelenen ağaç türlerinden birinin sarıçam olması ve bu türe ilişkin en başarılı fonksiyonların da Johnson SB ve Weibull fonksiyonları olması, Kastamonu yöresi sarıçam meşcereleri için benzer sonuçların elde edildiği bu çalışma ile önemli bir benzerlik ve uyum göstermektedir.

Ülkemizde gerçekleştirilen araştırmalara bakılacak olursa; Yavuz vd. (2002), doğal ve yapay dişbudak meşcerelerine ilişkin çap dağılımlarını modellemek üzere Gamma, Normal, Log-normal ve Weibull fonksiyonlarını karşılaştırarak gerek doğal gerekse yapay meşcereler için en başarılı tahminlerin Weibull dağılımı ile modellenebileceğini belirlemişlerdir. Sönmez vd. (2010) Artvin’deki Doğu ladini meşcerelerinin ve Doğdaş (2014) Ağlasun (Burdur) yöresi kızlçam meşcerelerinin çap dağılımlarının modellenmesinde Beta, Gamma, Johnson SB, Normal, Log-normal ve Weibull fonksiyonlarını karşılaştırmışlar ve her iki çalışmada da Johnson SB fonksiyonu diğer fonksiyonlara göre daha başarılı bulunmuştur. Seki (2021) ise Madra yöresi (İzmir) kızılçam meşcereleri için Gamma-2p, Gamma-3p, Johnson SB, Normal, Weibull-2p ve Weibull-3p fonksiyonlarını karşılaştırarak en başarılı tahminlerin Johnson SB fonksiyonu ile yapılabildiğini belirlemiştir. Sarıçamın karışıma dahil olduğu karışık meşcerelere ilişkin çap dağılımlarının modellendiği iki farklı çalışmada da Beta, Gamma, Johnson SB, Normal, Log-normal ve Weibull fonksiyonları karşılaştırılmıştır. Bu çalışmalarda sarıçam meşcereleri için en uygun fonksiyonlar, Doğu ladini-Sarıçam karışı meşcereleri için Weibull (Ercanlı ve Yavuz, 2010) ve Sarıçam-Doğu kayını karışık meşcereleri için ise Johnson SB (Kahriman ve Yavuz, 2011) olmuştur. Bu bilgilerden anlaşılacağı üzere, ulusal literatürde yer alan çalışmalara ilişkin sonuçlar da bu çalışmanın sonuçları ile benzerlik göstermektedir. Ancak, kızılçam meşcerelerinin çap dağılımlarının modellenmesi için Beta, Gamma, Normal, Log-normal ve Weibull fonksiyonlarının karşılaştırıldığı iki farklı araştırmanın sonuçları ise bu çalışmada elde edilen sonuçlardan farklılık göstermekte olup, Carus ve Çatal (2008) tarafından Ağlasun (Burdur) yöresi için yürütülen çalışmada Log-normal ve Güneş (2015) tarafindan Isparta yöresi için yürütülen çalışmada da Gamma dağılımları daha başarılı bulunmuştur. Log-normal ve Gamma fonksiyonları, Kastamonu yöresi sarıçam meşcerelerine yönelik bu çalışmada başarısız bulunan fonksiyonlardandır. Benzer şekilde, Sakıcı vd. (2016) tarafından Taşköprü (Kastamonu) yöresi karaçam meşcereleri için 9 farklı olasılık yoğunluk fonksiyonunun karşılaştıııldığı çalışmada da Johnson SB fonksiyonu başarılı fonksiyonlar arasında yer almasına karşın Gamma-3p fonksiyonundan daha başarısız tahminler sunmuştur.

Sakıcı (2021), Kastamonu yöresi değişikyaşlı göknar meşcerelerinin çap dağılımlarını modellemek üzere gerçekleştirdiği araştırmasında Eksponansiyel, Eksponansiyel-2p, Johnson SB, Weibull-2p ve Weibull-3p fonksiyonlarını karşılaştırmış ve ayrıca orta çap, ağaç sayısı, gögüs yüzeyi, sıklık ve meşcere tipi gibi meşcere özelliklerinin fonksiyonların başarı sıralamaları üzerindeki etkisini incelemiştir. Çalışma sonuçları, en başarılı çap dağılım tahminlerinin Johnson SB fonksiyonu ile elde edildiğini ve modellerin tahmin başarılarını etkileyen meşcere özelliğinin ise yalnızca meşcere tipi olduğunu ortaya koymuştur. Başarı sıralaması üzerinde meşcere tipinin etkili ve sıklığın ise etkisiz meşcere özellikleri olması her iki çalışmanın ortak bulgusu olmakla birlikte, 
söz konusu çalışmada etkisiz bulunan orta çap ve ağaç sayısı tarafımızca yapılan bu çalışmada önemli etkiye sahip meşcere özellikleri arasındadır.

\section{Sonuç ve Öneriler}

Çalışmada elde edilen sonuçlar, Kastamonu yöresi saf sarıçam (Pinus sylvestris L.) meşcerelerinin çap dağılımlarının modellenmesi için karşılaştırılan olasılık yoğunluk fonksiyonları arasında Johnson SB fonksiyonunun 1,75 başarı sırası ortalamasıyla en başarılı fonksiyon olduğunu ortaya koymuştur. Olasılık yoğunluk fonksiyonlarının başarı durumlarının meşcere özelliklerine göre değişimine ilişkin sonuçlar incelendiğinde ise ağaç sayısı, orta çap, kapalılık, gelişim çağı ve meşcere tipinin başarı sıralaması üzerinde etkili olduğu, buna karşın sıklık derecesi ve bonitet sınıfının sıralamaları etkilemediği belirlenmiştir.

Büyüme ve artım modellerinin önemli bir bileşeni olan çap dağılım modelleri meşcere yapılarının ortaya konulması ve meşcerelerden elde edilecek odun kökenli ürün çeşitlerinin belirlenmesi bakımından büyük öneme sahiptir. Ülkemizde çeşitli ağaç türlerinin farklı yayılış alanları için çap dağılım modelleri geliştirilmiş olmakla birlikte birçok orman ağacı türümüzün farklı yayılışları için bu çalışmaların henüz yapılmadığı bilinmektedir. Bu nedenle, çap dağılımları ile ilgili çalışmaların ülkemiz asli orman ağacı türleri ve bu türlerin farklı yayılış alanları için yapılması ormancılığımız açısından yararlı olacaktır.

Literatürde, bu çalışma kapsamında değerlendirilen olasılık dağılımları ve bunlara ilişkin yoğunluk fonksiyonlarının dışında çok sayıda dağılım fonksiyonu bulunmaktadır. Bu dağılımların çap dağılım modellemesinde kullanılabilirliklerinin araştırılması ormancılık literatürüne önemli katkılar sağlayacaktır. Bunun yanında, bu çalışmaya konu olasılık yoğunluk fonksiyonlarının parametrelerinin tahmininde kullanılan Maksimum Olabilirlik Yöntemi dışında farklı parametre belirleme yöntemleri de bulunmakta olup bu yöntemlerin gerek Kastamonu yöresi saf sarıçam meşcereleri için ve gerekse diğer ağaç türleri için incelenmesi de önemlidir.

Yapılan bu çalışmada elde edilen sonuçlar Kastamonu yöresi saf sarıçam meşcereleri için geçerli olup, bu sonuçların sarıçamın diğer yayılış alanlarında kullanılabilmesi için öncelikle uygunluklarının test edilmesi gerekmektedir. Ancak, Johnson SB fonksiyonunun esnek bir matematiksel forma sahip olduğu ve üzerinde araştırma yapılan birçok ağaç türü ve meşcere tipine uygun olduğu düşünüldüğünde muhtemelen ilerleyen süreçteki araştırmalarda da başarılı sonuçlar vereceği söylenebilir.

\section{Bilgilendirme}

Bu çalışma; Kastamonu Üniversitesi, Fen Bilimleri Enstitüsü, Orman Mühendisliği Anabilim Dalı'nda Esra DAL tarafından Doç. Dr. Oytun Emre SAKICI danışmanlığında hazırlanmış olan yüksek lisans tezinden üretilmiştir.

\section{Teşekkür}

Çalışmaya katkılarından dolayı Prof. Dr. Mehmet TOPAL, Dr. Öğr. Üyesi Muammer ŞENYURT ve Orman Müh. Gediz Metin KOCAELI'ye ve örnek alan karnelerinin temini konusundaki yardımlarından dolayı Orman Genel Müdürlüğü Orman İdaresi ve Planlama Dairesi Başkanlığı’na teşekkürlerimizi sunarız.

\section{Kaynaklar}

1. Alemdağ, İ. Ş. (1967). Türkiye'deki Sarıçam Ormanlarının Kuruluşu, Verim Gücü ve Bu Ormanların İsletilmesinde Takip Edilecek Esaslar. OGM Yayınları: Ankara, $160 \mathrm{~s}$.

2. Alkan, O. (2019). Toros Göknarı (Abies cilicica Carr.) Meşcereleri İçin Gövde Çapı, Çap-Boy, Çap Dağılım ve Bonitet Endeks Modellerinin Geliştirilmesi. Doktora Tezi, Isparta Uygulamalı Bilimler Üniversitesi Fen Bilimleri Enstitüsü, Orman Mühendisliği Anabilim Dalı, Isparta, 166 s.

3. Asan, Ü. (2013). Orman Amenajmanı Esasları. İstanbul Üniversitesi Yayınları: İstanbul, $274 \mathrm{s.}$

4. Bailey, R. L. (1980). Individual tree growth derived from diameter distribution models. Forest Science, 26(4), 626-632.

5. Bailey, R. L., Dell, T. R. (1973). Quantifying diameter distributions with the Weibull function. Forest Science, 19(2), 97-104. 
6. Bailey R. L., Abernethy N. C., Jones E. P. (1981). Diameter Distribution Models for Repeatedly Thinned Slash Pine Plantations. USDA Forest Service General Technical Reports, SO-34, 115-126.

7. Bliss, C. I., Reinker, K. A. (1964). A lognormal approach to diameter distributions in even-aged stands. Forest Science, 10(3), 350-360.

8. Bolat, F. (2014). Bursa-Kestel Orman İşletme Şefliği İçerisindeki Meşcereler İçin Çap Dağılım Modellerinin Geliştirilmesi. Yüksek Lisans Tezi, Çankırı Karatekin Üniversitesi Fen Bilimleri Enstitüsü, Orman Mühendisliği Anabilim Dalı, Çankırı, 85 s.

9. Bolat, F. (2021). Ankara Orman Bölge Müdürlüğü Anadolu Karaçamı Meşcerelerinde Artım Ve Büyümenin Yapay Sinir Ağları İle Modellenmesi. Doktora Tezi, Çankırı Karatekin Üniversitesi Fen Bilimleri Enstitüsü, Orman Mühendisliği Anabilim Dalı, Çankırı, 213 s.

10. Brooks, J. R., Borders, B. E., \& Bailey, R. L. (1992). Predicting diameter distributions for site-prepared loblolly and slash pine plantations. Southern Journal of Applied Forestry, 16(3), 130-133.

11. Bullock, B. P., Burkhart, H. E. (2005). Juvenile diameter distributions of loblolly pine characterized by the two-parameter Weibull function. New Forests, 29(3), 233-244.

12. Burk T. E., Newberry J. D. (1984). A simple algorithm for moment-based recovery of Weibull distribution parameters. Forest Science, 30(2), 329-332.

13. Burkhart, H. E. (1979). Growth and Yield of Southern Pines-State of The Art. Southern Forest Economists Workshop, 1-11, 21-22 March 1979, North Carolina, USA.

14. Burkhart, H. E., Tomé, M. (2012). Modeling Forest Trees and Stands. Springer: Dordrecht, 457 pages.

15. Cao, Q. V. (1997). A method to distribute mortality in diameter distribution models. Forest Science, 43(3), 435-442.

16. Carus, S. (1996). Aynı yaşlı doğu kayını (Fagus orientalis Lipsky). meşcerelerinde çap dağılımının bonitet ve yaşa göre değişimi. İstanbul Üniversitesi Orman Fakültesi Dergisi, 46(2), 171-182.

17. Carus, S., Çatal, Y. (2008). Kızılçam (Pinus brutia Ten.) meşcerelerinde 7-ağaç örnek nokta yöntemiyle meşcere ağaç sayısının çap basamaklarına dağılımının belirlenmesi. Süleyman Demirel Üniversitesi Orman Fakültesi Dergisi, 9(2), 158-169.

18. Carus, S., Çatal, Y. (2011). The Alteration of Diameter Distribution by Site Quality and Age in Even Aged Crimean Pine (Pinus nigra Arnold) Stands in Southern Turkey. 4th International Conference on Mediterranean Pines, 101-101, 6-10 June 2011, Avignon, France.

19. Chen, W. (2004). Tree size distribution functions of four boreal forest types for biomass mapping. Forest Science, 50(4), 436-449.

20. Clutter, J. L., Bennet, F. A. (1965). Diameter Distributions in Old-field Slash Pine Plantation. Georgia Forest Research Council, Report No: 13, USA.

21. Curtis, R. O., Clendenan, G. W., Demars, D. J. (1981). A New Stand Simulator for Coastal Douglas-fir: DFSIM User’s Guide. USDA Forest Service General Technical Reports, PNW-128, 79 pages.

22. Diamantopoulou, M. J., Özçelik, R., Crecente-Campo, F., Eler, Ü. (2015). Estimation of Weibull function parameters for modelling tree diameter distribution using least squares and artificial neural networks methods. Biosystems Engineering, 133, 33-45.

23. Doğdaş, İ. (2014). Burdur-Ağlasun Yöresi Kızılçam Ormanlarında Meşcere Ağaç Sayısı, Hacim ve Hacim Artımının Çap Basamaklarına Dağılımının Modellenmesi. Yüksek Lisans Tezi, Süleyman Demirel Üniversitesi Fen Bilimleri Enstitüsü, Orman Mühendisliği Anabilim Dalı, Isparta, 109 s.

24. Duan, A. G., Zhang, J. G., Zhang, X. Q., He, C. Y. (2013). Stand diameter distribution modelling and prediction based on Richards function. PLOS ONE, 8(4), e62605.

25. Eler, Ü. (2001). Orman Amenajmanı. Süleyman Demirel Üniversitesi Yayınları: Isparta, $274 \mathrm{s.}$

26. Eraslan, İ., Şad, H. C. (1993). Orman Amenajmanı. İstanbul Üniversitesi Yayınları: İstanbul, $420 \mathrm{~s}$.

27. Ercanlı, İ., Yavuz, H. (2010). Doğu ladini (Picea orientalis (L.) Link)-Sarıçam (Pinus sylvestris L.) karışık meşcerelerinde çap dağılımlarının olasılık yoğunluk fonksiyonları ile belirlenmesi. Kastamonu Üniversitesi Orman Fakültesi Dergisi, 10(1), 68-83.

28. Ercanlı, İ., Bolat, F., Kahriman, A. (2013). Comparing Parameter Recovery Methods for Diameter Distribution Models of Oriental Spruce (Picea orientalis (L.) Link.) and Scotch Pine (Pinus sylvestris L.) Mixed Stands Located Trabzon and Giresun Forest Regional Directorate. International Caucasian Forestry Symposium, 119-126, 23-26 October 2013, Artvin, Turkey.

29. Fonseca, T. F., Marques, C. P., \& Parresol, B. R. (2009). Describing maritime pine diameter distributions with Johnson's SB distribution using a new all-parameter recovery approach. Forest Science, 55(4), 367373.

30. Gadow, K. V., Hui, G. (1999). Modeling Forest Development. Springer: Dordrecht, 213 pages.

31. Gorgoso, J. J., González, J. Á., Rojo, A., Grandas-Arias, J. A. (2007). Modelling diameter distributions of Betula alba L. stands in northwest Spain with the two-parameter Weibull function. Forest Systems, 16(2), 113-123. 
32. Gorgoso, J. J., Rojo, A., Cámara-Obregón, A., Diéguez-Aranda, U. (2012). A comparison of estimation methods for fitting Weibull, Johnson's SB and beta functions to Pinus pinaster, Pinus radiata and Pinus sylvestris stands in northwest Spain. Forest Systems, 21(3), 446-459.

33. Gorgoso-Varela, J. J., Rojo-Alboreca, A., Afif-Khouri, E., Barrio-Anta, M. (2008). Modelling diameter distributions of birch (Betula alba L.) and pedunculate oak (Quercus robur L.) stands in northwest Spain with the Beta distribution. Forest Systems, 17(3), 271-281.

34. Güneş, S. (2015). Isparta Yöresi Kızılçam Meşcerelerinde Çap Dağılımının Örnek Nokta Ağaç Sayısına Göre Modellenmesi. Yüksek Lisans Tezi, Süleyman Demirel Üniversitesi Fen Bilimleri Enstitüsü, Orman Mühendisliği Anabilim Dalı, Isparta, $85 \mathrm{~s}$.

35. Hafley, W. L., Schreuder, H. T. (1977). Statistical distributions for fitting diameter and height data in even-aged stands. Canadian Journal of Forest Research, 7(3), 481-487.

36. Hyink, D. M., Moser, J. W. (1983). A generalized framework for projecting forest yield and stand structure using diameter distributions. Forest Science, 29(1), 85-95.

37. Johnson, N. L. (1949). System of frequency curves generated by methods of translation. Biometrika, 36, 149-176.

38. Kahriman, A., Yavuz, H. (2011). Sarıçam (Pinus sylvestris L.)-doğu kayını (Fagus orientalis Lipsky) karışık meşcerelerinde çap dağılımlarının olasılık yoğunluk fonksiyonları ile belirlenmesi. Artvin Çoruh Üniversitesi Orman Fakültesi Dergisi, 12(2), 109-125.

39. Kamziah, A. K., Ahmad, M. I., Ahmed Zuhaidi, Y. (2000). Modelling diameter distribution in even-aged and uneven-aged forest stands. Journal of Tropical Forest Science, 12(4), 669-681.

40. Kangas, A., Maltamo, M. (2000). Calibrating predicted diameter distribution with additional information. Forest Science, 46(3), 390-396.

41. Kapucu, F. (2004). Orman Amenajmanı. Karadeniz Teknik Üniversitesi Yayınları: Trabzon, 515 s.

42. Khongor, T., Lin, C., Tsogt, Z. (2011). Diameter structure analysis of forest stand and selection of suitable model. Mongolian Journal of Biological Sciences, 9(1-2), 19-22.

43. Laar, A., Akça, A. (2007). Forest Mensuration. Springer: Dordrecht, 383 pages.

44. Lawless, J. F. (1982). Statistical Models and Methods for Lifetime Data. Wiley: New York, 580 pages.

45. Lima, R. A. F., Batista, J. L. F., Prado, P. I. (2014). Modeling tree diameter distributions in natural forests: an evaluation of 10 statistical models. Forest Science, 61(2), 320-327.

46. Lima, R. B., Bufalino, L., Alves Junior, F. T., Silva, J. A. D., Ferreira, R. L. (2017). Diameter distribution in a Brazilian tropical dry forest domain: predictions for the stand and species. Anais da Academia Brasileira de Ciências, 89(2), 1189-1203.

47. Liu, C., Zhang, L., Davis, C. J., Solomon, D. S., Gove, J. H. (2002). A finite mixture model for characterizing the diameter distributions of mixed-species forest stands. Forest Science, 48(4), 653-661.

48. Liu, F., Li, F., Zhang, L., Jin, X. (2014). Modeling diameter distributions of mixed-species forest stands. Scandinavian Journal of Forest Research, 29(7), 653-663.

49. Loetsch, F., Zöhrer, F., Haller, K. E. (1973). Forest Inventory, Volume II. BLV: München, 469 pages.

50. Magnussen, S. (1986). Diameter distributions in Picea abies described by the Weibull model. Scandinavian Journal of Forest Research, 1, 493-502.

51. Maltamo, M. (1997). Comparing basal area diameter distributions estimated by tree species and for the entire growing stocks in mixed stand. Silva Fennica, 31(1), 53-65.

52. Maltamo, M., Puumalainen, J., Päivinen, R. (1995). Comparison of Beta and Weibull functions for modelling basal area diameter distribution in stands of Pinus sylvestris and Picea abies. Scandinavian Journal of Forest Research, 10, 284-295.

53. Mathwave (2015). EasyFit 5.5 Professional edition. www.mathwave.com

54. Mayrinck, R. C., Filho, A. C. F., Ribeiro, A., Oliveira, X. M. D., Lima, R. R. D. (2018). A comparison of diameter distribution models for Khaya ivorensis A. Chev. plantations in Brazil. Southern Forests, 80(4), 373-380.

55. Mısır, N. (2003). Karaçam Ağaçlandırmalarına İlişkin Büyüme Modelleri. Doktora Tezi, Karadeniz Teknik Üniversitesi Fen Bilimleri Enstitüsü, Orman Mühendisliği Anabilim Dalı, Trabzon, 222 s.

56. Nelson, T. C. (1964). Diameter distribution and growth of Loblolly pine. Forest Science, 10(1), 105-114.

57. OGM (2021). 2020 Türkiye Orman Varlı̆̆ı. OGM Yayınları: Ankara, 53 s.

58. Özçelik, R., Fidalgo Fonseca, T. J., Parresol, B. R., Eler, Ü. (2016). Modeling the diameter distributions of Brutian pine stands using Johnson's SB distribution. Forest Science, 62(6), 587-593.

59. Özdemir, G. A. (2016). Duglas (Pseudotsuga menziesii (Mirb.) Franco) meşcerelerinin çap dağılımlarının modellenmesi. İstanbul Üniversitesi Orman Fakültesi Dergisi, 66(2), 548-558.

60. Packard, K. C. (2000). Modeling Tree Diameter Distributions for Mixed-Species Conifer Forests in The Northeast United States. Master Thesis, State University of New York, USA, 128 pages.

61. Pogoda, P., Ochal, W., Orzel, S. (2019). Modeling diameter distribution of black alder (Alnus glutinosa (L.) Gaertn.) stands in Poland. Forests, 10(5), 412. 
62. Poudel, K. P., Cao, Q. V. (2013). Evaluation of methods to predict Weibull parameters for characterizing diameter distributions. Forest Science, 59(2), 243-252.

63. Rennolls, K., Geary, D. N., Rollinson, T. J. D. (1985). Characterizing diameter distributions by the use of the Weibull distribution. Forestry, 58(1), 57-66.

64. Reynolds, M. R., Burke, T. E., \& Huang, W. (1988). Goodness-of-tests and model selection procedures for diameter distribution models. Forest Science, 34(2), 373-379.

65. Sakıcı, O. E. (2021). A Comparison of Diameter Distribution Models for Uneven-aged Kazdağ Fir Stands in Kastamonu Region of Turkey. Global Conference on Engineering Research (GLOBCER'21), 578-590, 2-5 June 2021, Turkey.

66. Sakıcı, O. E., Seki, M., Sağlam, F., Akyıldız, M. H. (2016). Modeling Diameter Distributions of Black Pine Stands in Taşköprü Region. International Forestry Symposium, 521-535, 7-10 December 2016, Kastamonu, Turkey.

67. Sakıcı, O. E., Gülsunar, M. (2012). Diameter distribution of Bornmullerian fir in mixed stands. Kastamonu Üniversitesi Orman Fakültesi Dergisi, 12(3), 263-270.

68. Schreduer, H. T., Swank, W. T. (1974). Coniferous stands characterized with the Weibull distribution. Canadian Journal of Forest Research, 4(4), 518-523.

69. Scolforo, J. R. S., Tabai, F. C. V., Macedo, R. L. G., Acerbi, F. W., Assis, A. L. (2003). SB distribution's accuracy to represent the diameter distribution of Pinus taeda, through five fitting methods. Forest Ecology and Management, 175(1-3), 489-496.

70. Seki, M. (2021). Diameter Distribution of Calabrian Pine Stands in Madra, Western Turkey. International Congress on Environment, Disaster and Forest, 76, 20-21 October 2021, Adana, Turkey.

71. Siipilehto, J., Sarkkola, S., Mehtätalo, L. (2007). Comparing regression estimation techiques when predicting diameter distribution of Scots pine on drained peatlands. Silva Fennica, 41(2), 333-349.

72. Sivrikaya, F., Karakaş, R. (2020). Önsen doğal fistıkçamı (Pinus pinea L.) meşcerelerinde çap dağılımlarının modellenmesi. Turkish Journal of Forestry, 21(4): 364-372.

73. Sönmez, T., Günlü, A., Karahalil, U., Ercanlı, İ., Şahin, A. (2010). Saf Doğu Ladini Meşcerelerinde Çap Dağılımının Modellenmesi. III. Ulusal Karadeniz Ormancilık Kongresi, 388-398, 20-22 Mayıs 2010, Artvin.

74. The Jamovi Project (2019). Jamovi (Version 0.9) [Computer Software]. https://www.jamovi.org

75. Vanclay, J. K. (1994). Modelling Forest Growth: Applications to Mixed Tropical Forests. CAB International: Copenhagen, 312 pages.

76. Wang, M., Rennolls, K. (2005). Tree diameter distribution modelling: Introducing the logit logistic distribution. Canadian Journal of Forest Research, 35(6), 1305-1313.

77. Yavuz, H., Gül, A. U., Mısır, N., Özçelik, R., Sakıcı, O. E. (2002). Meşcerelerde Çap Dağılımlarının Düzenlenmesi ve Bu Dağılımlara İlişkin Parametreler ile Çeşitli Meşcere Özellikleri Arasındaki İlişkilerin Belirlenmesi. Orman Amenajmanında Kavramsal Açılımlar ve Yeni Hedefler Sempozyumu, 203-211, 18-19 Nisan 2002, İstanbul. 